\title{
A Phylogenetic Analysis of Doronicum (Asteraceae, Senecioneae) Based on Morphological, Nuclear Ribosomal (ITS), and Chloroplast (trnL-F) Evidence
}

\author{
Inés Álvarez Fernández,* Javier Fuertes Aguilar,* J ose L. Panero, † \\ and Gonzalo Nieto Feliner* \\ * Real Jardín Botánico, CSIC, Plaza de Murillo 2, 28014 Madrid, Spain; and †Integrative Biology Section, \\ School of Biological Sciences, University of Texas, Austin, Texas 78712
}

Received May 25, 2000; revised January 17, 2001; published online June 6, 2001

\begin{abstract}
A phylogenetic analysis of the Old World genus Doronicum ( 26 species, 4 subspecies) based on sequence data of the internal transcribed spacer (ITS) region of the nuclear ribosomal DNA, the chloroplast spacer trnL-F, and morphology is presented. Congruence among the three data sets was explored by the computing of several indices, all of which suggest homogeneity between only the two molecular matrices. We argue that the morphological data set contains poor phylogenetic signal and advocate simultaneous analysis of the three data sets (total evidence approach) so that morphological characters are tested for homology by congruence with molecular data. The resulting phylogenetic hypothesis allows several well-supported conclusions including the placement of a Corsican endemic (D. corsicum), sister to the remainder of the genus, and the inference that an early southern European or Mediterranean diversification took place in the genus. Shifts in morphological characters (e.g., homocarpy to heterocarpy) are confirmed to have evolved several times. Results from comparative studies of sequence data of the chloroplast gene $\mathrm{ndhF}$ support inclusion of Doronicum in tribe Senecioneae. (c) 2001 Academic Press
\end{abstract}

\section{INTRODUCTION}

The genus Doronicum comprises 26 species and 4 subspecies distributed in Asia, Europe, and north Africa (I. Álvarez, unpublished PhD dissertation). All the members of this genus are perennial, rhizomatous herbs bearing one to several radiate, yellow-flowered capitula. The involucre is composed of two or three rows of similar bracts. The plants occur in open or forested habitats from sea level up to $5000 \mathrm{~m}$ in elevation.

Despite old taxonomic misconceptions that allied Doronicum to genera as diverse as Arnica or Nannoglottis, the genus is now unanimously accepted as a mem- ber of tribe Senecioneae based on shared morphological, karyological, and chemical characters (Nordenstam, 1977; J effrey, 1987; Bremer, 1994).

Although several taxonomic studies circumscribing species from particular regions are available (Widder, 1925; Edmondson, 1973, 1975, 1978; Avetisyan, 1980; Chacón, 1987; Pérez Morales and Penas, 1990; Duvigneaud, 1992; Pérez Morales et al., 1994), there is only one previous comprehensive revision of Doronicum (Cavillier, 1907, 1911). This author included a hypothetical phylogenetic scheme for what he considered the core of the genus (his Sect. Doroni castrum), to the exclusion of his two monotypic sections, Soulieastrum (D. stenoglossum) and Hookerastrum. The latter section included a species that is currently placed in another genus, in a different tribe (Nannogl ottis hookeri, tribe Astereae). This classification was based almost exclusively on the shape of the basal leaves. This character is highly variable and thus a substantial portion of the species groupings based on it is likely to be the result of incorrect homology assessments. Cavillier (1911) recognized seven subsections. The species in subsection Plantaginea were suggested to be ancestral, having given rise to the rest of the subsections, some of them directly and some through subsection Grandiflorae Based on data presented here, none of Cavillier's subsections are monophyletic.

The main objective of this paper is to present a phylogenetic analysis of the genus based on three different data sets: morphology, the internal transcribed spacers (ITS) of the nuclear ribosomal DNA, and the chloroplast spacer region trnL-F. In addition, we present a preliminary assessment of the placement of Doronicum within the family based on the chloroplast gene ndhF. A few studies investigating relationships among genera of Asteraceae have sampled members of the Senecioneae but none of them have included Doronicum (J ansen et al., 1990, 1991; Kim et al., 1992; Kim and J ansen, 1995; Kadereit and J effrey, 1996). 
Integrating data from different sources into a single reliable estimate of phylogenetic relationships within a group of organisms is one the most intensively debated issues in phylogeny reconstruction (Bull et al., 1993; Eernisse and Kluge, 1993; Patterson et al., 1993; Olmstead and Sweere, 1994; De Queiroz et al., 1995; F arris et al., 1995; Huelsenbeck et al., 1996; Wiens, 1998; Slowinski and Page, 1999). However, there is no general agreement as to how such integration should be done. Some authors, representing the "total evidence" (character congruence, simultaneous analysis) approach, argue that all available data should be combined and analyzed simultaneously (Kluge and Wolf, 1993; Nixon and Carpenter, 1996). Other authors maintain that data from different sources should not be combined but should be independently analyzed (Miyamoto and Fitch, 1995), the latter representing the consensus approach (taxonomic congruence, partitioned analysis). A third, intermediate approach advocates merging the data into a single matrix only if there is evidence that the various matrices do not contain serious incongruence, i.e., that they do not represent different branching histories or that they have not been affected by different evolutionary mechanisms (Bull et al., 1993; J ohnson and Soltis, 1998).

In this paper, incongruence among the three different data sets is examined by use of several indices. Despite the fact that the two molecular data sets are incompatible with the morphological data set, we argue that the best solution for handling the three data sets is to combine them all into a single matrix. We discuss the reasons that justify our approach, including the apparently low phylogenetic signal contained in the morphological data and the homogeneity between two molecular markers with different modes of inheritance.

\section{MATERIAL AND METHODS}

\section{Plant Material and Data Sets}

F orty-five specimens representing the 26 species and 4 subspecies accepted in Doronicum and two outgroups (Ligularia sibirica and Tussilago farfara) were sampled (Table 1). Sequences from these specimens were included in the separate matrices of the ITS1 and ITS2, each containing more than one sample for each of several species, and are hereafter called the ITS extended matrices. To allow comparison and combination of the ITS data with both the trnL-F and the morphological data, the original extended ITS matrices were trimmed to include only 1 ITS sequence per taxon and combined to cover the whole ITS region (ITS1 + ITS2, the 5.8S excluded). This matrix is hereafter referred to as the ITS reduced matrix (Table 1 ). In those instances in which more than 1 specimen from the same species was sampled for the three markers, 1 of the specimens was arbitrarily chosen (Table 1). This was the case for both D. grandiflorum and D. austriacum. Based on the same criterion of use of the same samples in the three data sets (ITS, trnL-F, morphology) to allow combination, 3 species represented in the ITS extended matrices were removed from the ITS reduced matrix. These are D. carpaticum, D. cataractarum, and D. macrol epis (synonym of D. macrophyllum in our taxonomic treatment), for which we repeatedly failed to amplify the trnL-F. In contrast, a representative sample of $D$. turkestanicum, from Xinjiang (China), was included in the reduced matrix despite our taxonomic treatment which considers this taxon a synonym of the central Asian species D. falconeri (Table 1). With these adjustments, the resulting reduced matrix contains $30 \mathrm{se}-$ quences of Doronicum plus the two outgroup species.

In addition to trnL-F, another chloroplast region was assayed for variation within Doronicum. The trnT-L spacer (Taberlet et al., 1991) was sequenced in samples of 14 species of Doronicum. Although the sequences ranged in length from 529 to 545 bp, only five positions were variable, and they have no phylogenetic value as they represent autapomorphies. In addition, there are two regions that contain poly $(T)$ and poly(A) stretches and require gaps of different length for alignment. This marker was eventually abandoned because of lack of informative variation.

The morphological data set has been elaborated on the basis of a comprehensive taxonomic revision of the genus and thus is based on the study of ca. 4300 herbarium specimens (I . Álvarez, unpublished PhD dissertation). Features that are autapomorphic, quantitative, continuous, plastic, intraspecifically polymorphic, and seemingly nonhomologous were trimmed from a raw matrix containing 51 characters. As a result, the morphological data set contains only 12 characters (Table 2).

Ligularia sibirica and Tussilago farfara, both members of the Old World Senecioneae-Tussilagininae (Bremer, 1994), were chosen as outgroups. Several attempts were made to align the ITS sequences of Doronicum with those of other genera of Senecioneae suggested in the literature as closely related to the genus. Sequences from other tribes were also examined. These include Psacalium, Roldana, and Tephroseris in the Tussilagininae, Gynura, Packera, and Pericallis in the Senecioninae, and Arnica (Helenieae), Calendula (Calenduleae), and Myriactis (Astereae). These sequences were provided by J. Panero and J. Francisco-Ortega (Psacalium, Tephroseris, Gynura, Packera, Roldana, Pericallis) and retrieved from GenBank (Arnica, Calendula, Myiriactis). Unambiguous alignment of any of those sequences with Doronicum by visual inspection or with CLUSTALW was not possible, thus suggesting distant relationships to our study genus. 
TABLE 1

Specimens Sampled in This Study

\begin{tabular}{|c|c|c|c|c|}
\hline Taxon & Geographic origin $^{a}$ & Marker & ACRONYM ${ }^{b}$ & GenBank Accession No. \\
\hline D. altaicum & Siberia, Altai, river Surijza & ITS1, ITS2, trnL-F & ALTA & AJ 400002, AJ 400048, AJ 400104 \\
\hline D. atlanticum & Algeria, Djurdjura, Tala Guilef & ITS1, ITS2, trnL-F & ATLA & AJ 400003 , AJ 400049 , AJ 400105 \\
\hline D. austriacum & Greece, Makedonien, Nomos Florinis & ITS1, ITS2, trnL-F & AUS1 & AJ 400004, AJ 400050, AJ 400106 \\
\hline D. austriacum & Poland, Bieszczady & ITS1, ITS2 & AUS2 & A) 400005 , AJ 400051 \\
\hline D. briquetii & China, Tibet-Qinghai, Tha Chu valley & ITS1, ITS2, trnL-F & BRIQ & AJ 400006, AJ 400052, AJ 400107 \\
\hline D. cacaliifolium & Turkey, Isauria, Vil Antalya & ITS1, ITS2, trnL-F & CACA & Aj 400007, Aj 400053, Aj 400108 \\
\hline D. carpaticum & Romania, Comit, Fogaras & ITS1, ITS2 & CRTC & A) 400008 , Aj 400054 \\
\hline D. carpetanum subsp. carpetanum & Spain, Madrid, Sierra de Guadarrama & ITS1, ITS2, trnL-F & CARP & AJ 400009, AJ 400055, AJ 400109 \\
\hline D. carpetanum subsp. diazii & Spain, Soria, Picos de Urbión & ITS1, ITS2, trnL-F & DIAZ & Aj 400014 , Aj 400060 , Aj 400113 \\
\hline D. carpetanum subsp. kuepferi & Spain, Ávila, Sierra de Béjar & ITS1, ITS2, trnL-F & KUE 1 & AJ 400024, AJ 400070, AJ 400120 \\
\hline D. carpetanum subsp. kuepferi & Spain, Ávila, Sierra de Béjar & ITS1, ITS2 & KUE2 & Aj 400025, Aj 400071 \\
\hline D. carpetanum subsp. kuepferi & Spain, Ávila, Sierra de Gredos & ITS1, ITS2 & KUE3 & AJ 400026, AJ 400072 \\
\hline D. carpetanum subsp. pubescens & Spain, León, Cordillera Cantábrica & ITS1, ITS2, trnL-F & PUBE & AJ 400039, AJ 400085, AJ 400095 \\
\hline D. cataractarum & Austria, Koralpe & ITS1, ITS2 & CATA & A) 400010, AJ 400056 \\
\hline D. cavillieri & China North-central, Lianhuashan & ITS1, ITS2, trnL-F & CAVI & AJ 400044, AJ 400090, AJ 400100 \\
\hline D. clusii & Italy, Bormio, Passo dello Stelvio & ITS1, ITS2, trnL-F & CLUS & AJ 400011, AJ 400057, AJ 400110 \\
\hline D. columnae & Italy, Trento, Passo Gardena & $\begin{array}{l}\text { ITS1, ITS2, trnL-F, } \\
\text { ndhF }\end{array}$ & COLU & $\begin{array}{l}\text { AJ } 400012 \text {, AJ } 400058, \text { AJ } 400111 \text {, } \\
\text { AJ } 276493\end{array}$ \\
\hline D. corsicum & Corsica, mount Renoso & ITS1, ITS2, trnL-F & CORS & AJ 400013 , AJ 400059 , AJ 400112 \\
\hline D. dolichotricum & Caucasus, Transcaucasus, Gruziya & ITS1, ITS2, trnL-F & DOLI & A) 400015 , AJ 400061 , AJ 400114 \\
\hline D. falconeri & Pakistan, Nanga Parbat & ITS1, ITS2, trnL-F & FALC & AJ 400016 , AJ 400062 , Aj 400115 \\
\hline D. falconeri (sub. D. turkestanicum ${ }^{\mathrm{c}}$ ) & $\begin{array}{l}\text { China, Xinjiang, Uygur Zizhiqu, } \\
\text { Tien Shan }\end{array}$ & ITS1, ITS2, trnL-F & TURK & AJ 400045, AJ 400091, AJ 400101 \\
\hline D. glaciale & Italy, Trento, Col Rodella, & ITS1, ITS2, trnL-F & GLAC & AJ 400017, AJ 400063, AJ 400116 \\
\hline D. grandiflorum & Spain, Asturias, Picos de Europa & $\operatorname{trnL}-\mathrm{F}$ & GRA1 & A) 400117 \\
\hline D. grandiflorum & France, Pyrenees, Vallée d’Ossoue & ITS1, ITS2 & GRA2 & AJ 400018, AJ 400064 \\
\hline D. grandiflorum & Andorra, Pyrenees, circo de Pessons & ITS1, ITS2 & GRA3 & A) 400019 , AJ 400065 \\
\hline D. grandiflorum & Spain, Huesca, Pyrenees, peak Aneto & ITS1, ITS2 & GRA4 & Aj 400020, Aj 400066 \\
\hline D. grandiflorum & Spain, Girona, Pyrenees, peak Noufonts & ITS1, ITS2 & GRA5 & A) 400021 , AJ 400067 \\
\hline D. haussknechtii & Turkey, Giresun, Karagöl & ITS1, ITS2, trnL-F & HAUS & AJ 400022 , AJ 400068 , AJ 400118 \\
\hline D. hungaricum & Romania, Oltenia, Craiova & ITS1, ITS2, trnL-F & HUNG & AJ 400023, AJ 400069, AJ 400119 \\
\hline D. kamaonense & J ammu-Kashmir, Sind Valley & ITS1, ITS2, trnL-F & KAMA & Aj 400041 , Aj 400087 , Aj 400097 \\
\hline $\begin{array}{l}\text { D. macrophyllum subsp. macrophyllum } \\
\left({\left.\text { (sub D. macrol epis }{ }^{c}\right)}^{\text {a }}\right.\end{array}$ & Turkey, Boejuk dere supra Artabir & ITS1, ITS2 & MCRL & A) 400027 , AJ 400073 \\
\hline D. macrophyllum subsp. macrophyllum & Caucasus, Transcaucasus, Azerbaydzhan & ITS1, ITS2, trnL-F & MACR & AJ 400028, AJ 400074, AJ 400121 \\
\hline D. macrophyllum subsp. sparsipilosum & Turkey, Çankiri, Ilgaz Kastamonu & ITS1, ITS2, trnL-F & SPAR & AJ 400042 , AJ 400088 , AJ 400098 \\
\hline D. maximum & Turkey, Erzurum & ITS1, ITS2, trnL-F & MAXI & AJ 400029, AJ 400075, AJ 400122 \\
\hline D. oblongifolium & Caucasus, Transcaucasus, Armeniya & ITS1, ITS2, trnL-F & OBLO & A) 400030 , AJ 400076 , AJ 400123 \\
\hline D. orientale & Greece, Arcadia, mount Melanon & ITS1, ITS2, trnL-F & ORIE & Aj 400031 , Aj 400077 , Aj 400124 \\
\hline D. pardalianches & Spain, Huesca, sierra de Guara & ITS1, ITS2, trnL-F & PAR 1 & AJ 400032, AJ 400078, AJ 400125 \\
\hline D. pardalianches & Spain, Lleida, Sierra del Cadi & ITS1, ITS2 & PAR2 & A) 400033 , AJ 400079 \\
\hline D. plantagineum & Spain, Almería, sierra de Gádor & ITS1, ITS2, trnL-F & PLA1 & AJ 400034, AJ 400080, AJ 400094 \\
\hline D. plantagineum & Spain, Murcia, Moratalla & ITS1, ITS2 & PLA2 & A) 400035, AJ 400081 \\
\hline D. plantagineum & Spain, Asturias, Cordillera Cantábrica & ITS1, ITS2 & PLA3 & AJ 400036, AJ 400082 \\
\hline D. plantagineum & Spain, Guadalajara, Cantalojas & ITS1, ITS2 & PLA4 & AJ 400037 , AJ 400083 \\
\hline D. plantagineum & Spain, Montes de Toledo & ITS1, ITS2 & PLA5 & Aj 400038, AJ 400084 \\
\hline D. reticulatum & Turkey, Bursa, Belvedere & ITS1, ITS2, trnL-F & RETI & AJ 400040, AJ 400086, AJ 400096 \\
\hline D. stenoglossum & China, Tibet-Qinghai, Dari Xian & ITS1, ITS2, trnL-F & STE $N$ & AJ 400043 , AJ 400089 , AJ 400099 \\
\hline Ligularia sibirica & France, Pyrenees, Capcir & ITS1, ITS2, trnL-F & LIGU & Aj 400046, AJ 400092, AJ 400102 \\
\hline Tussilago farfara & Spain, Cuenca, El Cubillo & ITS1, ITS2, trnL-F & TUSS & A) 400047, AJ 400093 , AJ 400103 \\
\hline
\end{tabular}

\footnotetext{
${ }^{a}$ Main geographic subdivisions follow Hollis and Brummitt (1992).

${ }^{\mathrm{b}}$ Samples included in the ITS reduced matrix (see text) are in boldface.

${ }^{\mathrm{c}}$ In the trees and appendixes.
}

\section{DNA Extraction, Amplification, and Sequencing}

Total DNA was extracted both from living plants and from herbarium material following the CTAB method of Doyle and Doyle (1987). A sample of 30-50 mg of leaf material from each of the specimens was used.

Amplification of the whole ITS region (ITS1 + 5.8S + ITS2) was performed with primers ITS7A (White et al., 1990) slightly modified by J. L. Panero and A. Plovanovich-J ones (pers. comm.) and ITS4 (White et al., 1990). However, in most cases ITS1 and ITS2 spacers were amplified separately with primers ITS7A and ITS2 for ITS1 and with ITS3 and ITS4 for ITS2. The trnT-L spacer region was amplified with primers $a$ and $b$, and trnL-F was amplified with primers e and $f$ (Taberlet et al., 1991). For ITS, the PCR cocktail followed Kim and $J$ ansen (1994). For trnT-L and trnL-F, we followed Taberlet et al. (1991). When a first amplification of ITS was not adequate, $5-10 \%$ of dimethyl sulfoxide was added to the cocktail in a new reaction. The standard PCR program for ITS amplification began with $1 \mathrm{~min}$ 


\section{TABLE 2}

\section{Characters Included in the Morphological Data Set}
1. Rhizome hairy on the nodes (1); rhizome glabrous on the nodes (0).
2. Rhizome with unequal internodes, thin and long internodes alternating with short and wide internodes (1); rhizome with internodes uniform in length and width (0).
3. Rhizome with buds (1); rhizome without buds (0).
4. Basal leaves with three main nerves converging toward the apex (triplinerved) (1); basal leaves with other venation pattern (0).
5. Basal leaves with pinnate-reticulate venation (1); basal leaves with other venation pattern (0).
6. Scapiform stems (most leaves basal) (1); stems leafy (0).
7. Tall herbs with one to four very large reticulately veined caulinar leaves and several to many capitula (1); other architecture (0).
8. I nvolucral bracts ciliate (1); involucral bracts not ciliate (0).
9. Homocarpic capitula (1); heterocarpic capitula (marginal cypselae thicker and epappose) (0).
10. Cypselae with glands (1); cypselae without glands (0).
11. Involucre with shorter supplementary bracts at base (0); involucre without shorter supplementary bracts (1).
12. Involucral bracts in two to three rows (1); involucral bracts in one row (0).

at $94^{\circ} \mathrm{C}, 40 \mathrm{~s}$ at $92^{\circ} \mathrm{C}, 40 \mathrm{~s}$ at $50^{\circ} \mathrm{C}, 90 \mathrm{~s}$ at $75^{\circ} \mathrm{C}$, followed by 29 cycles of $40 \mathrm{~s}$ at $92^{\circ} \mathrm{C}, 40 \mathrm{~s}$ at $50^{\circ} \mathrm{C}$, and $90 \mathrm{~s}$ at $75^{\circ} \mathrm{C}$. The program was completed with $5 \mathrm{~min}$ at $75^{\circ} \mathrm{C}$ and then held at $4^{\circ} \mathrm{C}$. In many cases this protocol was modified to make it suitable for specific samples. For trnL-F and trnT-L amplification, we followed the PCR cycle profile proposed by Taberlet et al. (1991). The PCR products were purified either by centrifugation with Millipore Ultrafree-MC 30,000 NMWL cellulose filters or with a Boehringer Mannheim PCR Clean Up Kit. In both cases we followed manufacturer's recommendations.

ITS amplification of recalcitrant samples or those for which DNA was isolated from herbarium specimens required additional manipulation and purification via cloning to obtain readable sequences. Approximately $48 \%$ of the ITS sequences used in this study were cloned. Ligation and transformation reactions were performed with the Invitrogen TOPO TA Cloning Kit Version D. Transformed bacteria were spread on LB plates containing ampicillin $(100 \mathrm{mg} / \mathrm{ml})$, and colonies with inserts were raised on new plates. Approximately 10 of these colonies were screened via PCR for the presence of the ITS insert with primers ITS5 and ITS4. The PCR protocol followed with the selected colonies was the same as that above except for the thermocycler program. After a $10-\mathrm{min}$ hot start at $94^{\circ} \mathrm{C}$, Taq polymerase was added. An initial step of $5 \mathrm{~min}$ at $57^{\circ} \mathrm{C}$ was followed by $30 \mathrm{cycles}$ at $94^{\circ} \mathrm{C}$ for $1 \mathrm{~min}, 57^{\circ} \mathrm{C}$ for $1 \mathrm{~min}$, and $72^{\circ} \mathrm{C}$ for $1 \mathrm{~min}$. Colonies with desired inserts were grown in LB liquid medium with ampicillin for approximately $12 \mathrm{~h}$ at $250 \mathrm{rpm}$ and $37^{\circ} \mathrm{C}$. Plasmids were harvested with the Promega Wizard Plus SV Minipreps kit under the specified protocol. To amplify cloned fragments, a PCR was prepared with $1 \mu$ of plasmid and universal primers M 13F and M 13R for the plasmid. PCR products were digested with restriction enzyme Spel (New England BioLabs) to discriminate for desired ITS sequence as all Doronicum species have a conserved Spel site in their ITS1 region.

For directly sequenced samples, nucleotide se- quences of both strands were determined from PCR fragments with the dideoxy chain termination method (Sanger et al., 1977). The sequencing primers used for amplification were the same as those above. Standard protocols of the manufacturer for Taq DNA polymerase-initiated cycle sequencing reactions with fluorescently labeled dideoxynucleotide terminators (Applied Biosystems) were followed. For cloned sequences, purified PCR products were sequenced with a dye terminator cycle-sequencing ready-reaction kit (PerkinElmer, Applied Biosystems Division). Sequencing products were separated and analyzed on an ABI 377 Automated DNA sequencer (Perkin-Elmer, Applied Biosystems Division) at the Institute of Cellular and Molecular Biology of the University of Texas at Austin. Chromatograms were examined and edited with E ditView (Applied Biosystems) and Sequencher (Gene Codes Corp., Ann Arbor, MI). All the sequences were recorded in both strands with a 100\% overlap. The 125 sequences have been submitted to the EMBL database (Table 1).

\section{Data Analysis}

Alignment of the sequences was performed manually (Appendixes 1 and 2). It was relatively easy for Doronicum but somewhat more challenging for outgroups in variable domains of the ITS. Pairwise distance values between sequences were calculated with the Kimura two-parameter model as implemented by PAUP $4.0 \mathrm{~b} 2$ for Power PC (Swofford, 2000) for all data sets.

Phylogenies were reconstructed by the application of the Fitch parsimony criterion (unordered characterstates, equal weights) as implemented by PAUP. Searches for the most parsimonious trees (m.p.t.) in the analysis of the different data sets were performed with the heuristic algorithm and the TBR and MULPARS options in effect. ACCTRAN option was used for character optimization. To attempt to locate trees on multiple islands of most parsimonious trees (Maddison, 1991), 10 replicate searches with random taxon addition were performed. Gaps were treated as 
missing data. Bootstrap analysis was performed to assess relative branch support from the data. In half of the analyses, bootstrap values were obtained from PAUP with 100 replicates, each with 10 random taxon addition and the TBR and MULPARS options in effect. However, we compared these bootstrap values with those obtained by the fast bootstrap option in PAUP (10,000 replicates) and found that they were very similar. This is consistent with an empirical study by Mort et al. (2000) that compared fast bootstrap approaches with those obtained by branch-swapping. Thus, the remaining bootstrap analyses of the morphological matrix, the trnL-F, and the ITS1 and ITS2 extended matrices were calculated with the fast bootstrap method. A successive weighting procedure (Farris, 1969) was followed in PAUP to try to reduce the effects of the most homoplastic characters in the mor phological data set. We reweighted characters with the rescaled consistency index until the weights assigned to each character were identical in two successive iterations, thus resulting in the same number of m.p.t. and length. To check for consistency in the topology with other methods of phylogeny reconstruction, a neighbor-joining tree was constructed based on pairwise sequence distances within the ITS reduced matrix.

\section{Congruence among Data Sets}

To examine the feasibility of integrating the three data sets into a single matrix for estimating phylogenetic relationships within Doronicum, all possible combinations of the three data sets were analyzed with parsimony and the results compared. In these independent and combined analyses, the data set used for the ITS marker was the reduced matrix (32 taxa).

Several indices that assess the degree of congruence between data sets for the same organisms were also calculated (J ohnson and Soltis, 1998). We computed two topological congruence indices. The partition metric (PM) measures the rearrangements needed to transform one of the two trees that we compared into the other (Robinson and F oulds, 1981). The other topological index used is the greatest agreement subtree metric, $D_{1}$ (Kubicka et al., 1995). It measures the number of taxa that we have to prune in two trees to arrive at a minimum topology in which the two trees agree. Both topological indices were computed in PAUP under the "tree to tree distances" menu, with the "symmetricdifference distance" and "agreement metric D1" commands, respectively. To maintain a reasonable number of pairwise comparisons with the molecular trees, only the 52 m.p.t. obtained after three rounds of the successive weighting procedure on the morphological matrix were considered in these topological indices.

To address the question of how much conflicting phylogenetic information exists between two data sets rather than how different are two phylogenetic trees derived from them, we calculated other indices that are more directly based on the data sets. The incongruence metric of Miyamoto, I M (Miyamoto in Swofford, 1991), calculates the extra homoplasy needed to explain each data set on the topol ogy recovered from the alternative data set. For the ITS/trnL-F comparison, this means the number of homoplastic steps required to explain the ITS data set on the most parsimonious tree(s) recovered from the trnL-F data set, plus the number of homoplastic steps required to map the trnL-F data on the most parsimonious tree(s) recovered from the ITS data. The incongruence metric of Mickevich and Farris $\left(I_{\mathrm{MF}}\right)$ (Mickevich and Farris, 1981) is similar but instead of mapping each data set on the other data set, it uses the number of homoplastic steps required by each individual data set to explain the shortest tree recovered from the combined matrix. Both indices were computed with the length and fit measures given by PAUP and following the indications by J ohnson and Soltis (1998).

We also applied a significance test for heterogeneity that addresses the problem of how large a character congruence index needs to be to indicate a serious conflict between data sets. We used the test proposed by Farris et al . (1995) based on the incongruence length difference of Mickevich and Farris $\left(\mathrm{I}_{\mathrm{MF}}\right)$. This test is implemented in PAUP as the "partition homogeneity test" and referred to as $\mathrm{HT}_{\mathrm{F}}$ by J ohnson and Soltis (1998). The $I_{M F}$ metric is computed for a number of random partitions of the combined data set, each partition consisting of two subsets of the same size as the two data sets. When $95 \%$ or more of those random partitions show an $\mathrm{I}_{\mathrm{MF}}$ smaller than the original, we reject the null hypothesis and conclude that the data sets are significantly heterogeneous. This test was computed by execution of the "partition homogeneity test" command in PAUP on each of the three combined matrices (ITS + trnL-F, ITS + morphology, trnL-F + morphology).

\section{Placement of Doronicum}

For a preliminary assessment of the placement of Doronicum within the Senecioneae, the chloroplast gene ndhF was used. Because the last $800 \mathrm{bp}$ of the gene are the most variable (Kim and J ansen, 1995), we initially sequenced this portion in two morphologically distinct species (D. columnae and D. stenoglossum), placed in different clades in the ITS trees. For amplification, we used primers 1201 and 1417 kindly provided by R. K. J ansen and based on the coding sequence of tobacco (Shinonzaki et al., 1986). The sequences in both species are identical, and we therefore sequenced the entire gene only for $D$. columnae using primers 52 and 590 . The $2.2-\mathrm{kb}$ sequence was aligned with a representative selection of the Asteraceae matrix generated by Kim and J ansen (1995). The matrix that we analyzed included 2238 characters and 59 terminals, 5 of them outside Asteraceae (Boopis, 
Campanula, Dampiera, Menyanthes, and Scaevola) which were used as outgroups. A parsimony heuristic search, with the same options as for the analysis within Doronicum, was conducted with PAUP.

\section{RESULTS}

\section{ITS Sequences}

The total aligned length of the ITS sequence, excluding the $5.8 \mathrm{~S}$ gene, is 496 positions, corresponding to 265 bp in ITS1 and 231 bp in ITS2. Within Doronicum, ITS1 is 255-260 bp (D. atlanticum and D. oblongifolium), and ITS2 ranges from 210 bp (D. columnae, D. macrophyllum) to 214 bp (D. briquetii and several others). I $n$ all, 12 indels were required for the alignment of the ITS region. In ITS1, 3 are 2 bp in length, and 1 is $3 \mathrm{bp}$. In ITS2, 4 are $1 \mathrm{bp}, 3$ are $2 \mathrm{bp}$, and 1 is $3 \mathrm{bp}$. Eighty-eight variable positions (33.2\%) within Doronicum are found in the ITS1 extended matrix, 53 of which are autapomorphic. Sixty-two variable positions (26.8\%) within Doronicum are found in the ITS2 extended matrix, 33 of which are autapomorphic. When the reduced matrix (ITS1 + ITS2) is considered, the following features are obtained: 144 variable positions (29\%) within Doronicum, 89 of which are autapomorphic and 55 of which are potentially informative within the ingroup in a parsimony analysis. Four polymorphisms were detected that follow an additive pattern with respect to extant taxa. This feature increases to eight when the ITS1 and ITS2 extended matrices are considered.

ITS pairwise distance values within Doronicum, calculated separately for the two spacers, range from 0 to 0.115 in ITS1 and from 0 to 0.13 in ITS2. The greatest distance was found between D. corsicum and D. macrophyll um subsp. sparsipi l osum in ITS2. Distances between sequences from the same taxon range from 0 to 0.023 in ITS1 and from 0 to 0.024 in ITS2. In particuIar, within D. austriacum divergence was 0.023 in ITS1 and 0.024 in ITS2, within D. grandiflorum it was 0 in ITS1 and ranged from 0 to 0.009 in ITS2, within D. pardalianches it was 0 in ITS1 and 0.004 in ITS2, within D. plantagineum it was 0 to 0.003 in ITS1 and 0 to 0.014 in ITS2, and within D. carpetanum subsp. kuepferi it was 0 in both ITS1 and ITS2. When the ITS1 + ITS2 reduced matrix is considered, the distances range from 0.002 to 0.114 . The shortest distance between a species of Doronicum and the outgroup was displayed by $\mathrm{D}$. corsicum $(0.26$ with respect to Ligularia sibirica in the reduced matrix).

Parsimony analysis of ITS1, including all sequences, i.e., 46 terminals from 35 taxa, resulted in 1492 optimal trees (length $=143 ; \mathrm{Cl}$, excluding autapomorphic characters $=0.68 ; \mathrm{RI}=0.83)$. Unambiguous resolution is modest (tree not shown). However, the most strongly supported phylogenetic conclusions reported in this pa-

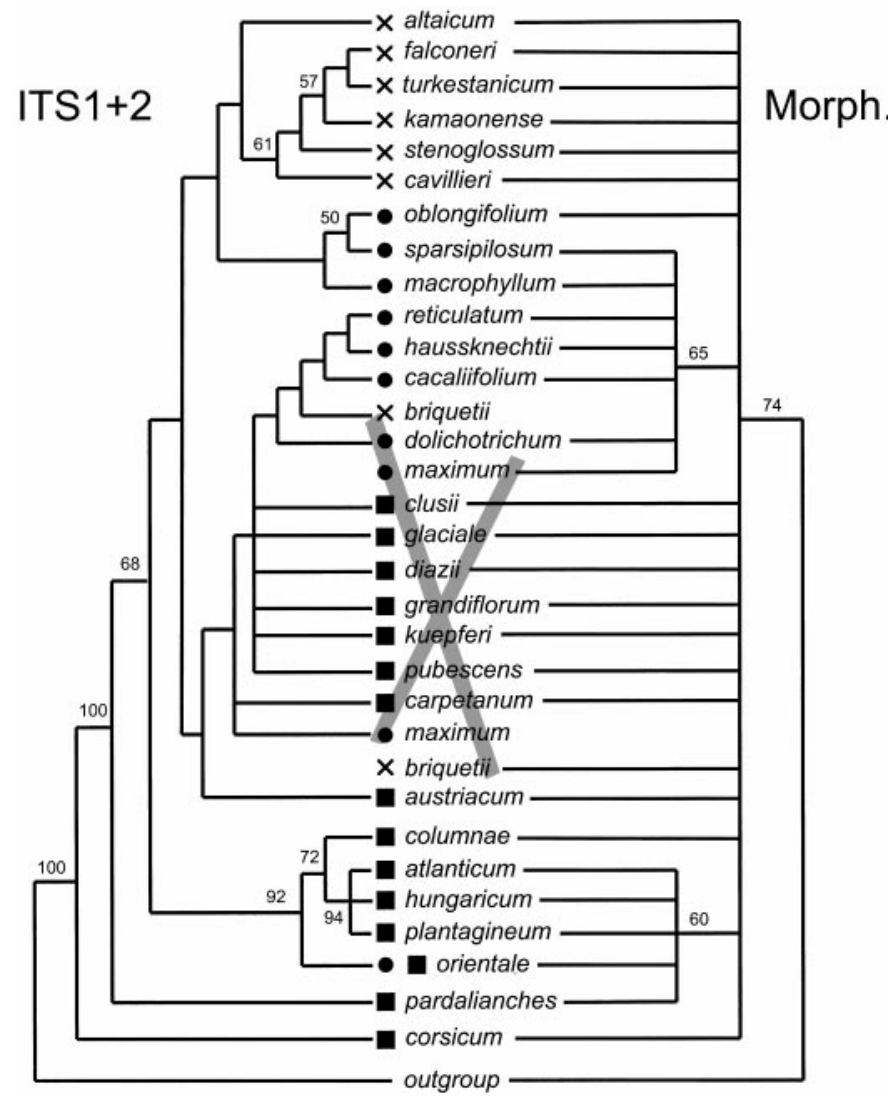

FIG. 1. Congruence between data sets in Doronicum: Comparison of the strict consensus trees from the independent analyses of the internal transcribed spacers (ITS) of the nrDNA and a morphological data set. Taxa represented twice to allow comparison of the two trees are linked by gray lines. Bootstrap values above $50 \%$ are shown along the branches. Geographical distribution of the taxa analyzed: central and eastern Asia (crosses), southwest Asia (circles), and Europe and northern Africa (squares).

per are al ready apparent or suggested in this analysis. These are the monophyly of Doronicum relative to the outgroups included, the basal position of D. corsicum, the D. plantagineum clade, and the relationship between some of the central and eastern Asian taxa.

The ITS2 extended matrix (46 sequences from 35 taxa) analyzed under parsimony resulted in 1118 optimal trees (length $=95 ; \mathrm{Cl}$, excluding autapomorphic characters $=0.71 ; \mathrm{RI}=0.86)$. As with ITS1, the strict consensus shows moderate resolution, and the first two of the phylogenetic conclusions mentioned hold (tree not shown).

When the reduced matrix (32 sequences) was analyzed under parsimony, the number of most parsimonious trees dropped to 12 , and the resolution increased compared to the independent analyses of the two spacers (Fig. 1) while homoplasy and length increased (length = 373; $\mathrm{Cl}$, excluding autapomorphic characters $=0.61 ; \mathrm{RI}=0.72$ ). Bootstrap support above $90 \%$ is limited to the Doroni cum clade (the ingroup), the same 
clade excluding D. corsi cum, and the clade including D. plantagineum, D. hungaricum, D. atlanticum, D. columnae, and D. orientale (hereafter called the D. plantagineum clade).

The topology of the neighbor-joining tree from the analysis of the ITS reduced matrix is largely consistent with the strict consensus tree from the parsimony analysis of the same matrix (tree not shown). The only difference is the placement of D. austriacum, which appears on a deep node in both analyses. In the parsimony tree, D. austriacum is sister to a large clade comprising seven European taxa, five southwestern Asian taxa, and a single central Asian taxon, D. briquetii (Fig. 1). In the neighbor-joining tree, D. austriacum appears as sister to the clade including the six remaining central and eastern Asian taxa (D. altaicum, D. falconeri, D. turkestani cum, D. kamaonense, D. stenoglossum, and D. cavillieri) and three southwestern Asian taxa (D. oblongifolium, and D. macrophyllum subsp. macrophyllum and subsp. sparsi pilosum). However, such a difference in topology between the neighbor-joining and the parsimony trees is negligible given that the clades that include D. austriacum in both analyses receive bootstrap support $<5 \%$.

\section{TrnL-F Sequences}

Length of the spacer ranges from 348 bp (D. pardalianches) to $381 \mathrm{bp}$ (D. altaicum). Total aligned length of the trnL-F is $397 \mathrm{bp}$. It includes six gaps, of which two are $1 \mathrm{bp}$, and the remaining four are 8, 9, 10, and $25 \mathrm{bp}$. Twelve positions (3\%) are variable within Doronicum, of which 9 are autapomorphic and 3 are potentially informative in a parsimony analysis. Pairwise distance values are considerably lower than those in ITS, ranging from 0 to 0.019 . The greatest distance is displayed between D. corsicum and D. cacaliifolium. The parsimony analysis of the trnL-F sequences resulted in 18 m.p.t. (length $=28 ; \mathrm{Cl}$, excluding autapomorphic characters $=0.90 ; \mathrm{RI}=0.94$ ). Resolution was very poor. In the strict consensus tree, only three clades were recovered: the Doronicum clade (100\% bootstrap), the Doronicum clade excluding D. corsicum (91\% bootstrap), and a small clade composed of $D$. hungaricum and D. plantagineum (63\% bootstrap) (see majority rule consensus in Fig. 2).

\section{Morphological Data}

Given that 2 of the characters in the morphological data set are synapomorphic for the entire genus, only 10 characters are potentially informative within Doronicum. The parsimony analysis resulted in 675 m.p.t. (length $=20 ; \mathrm{Cl}=0.60 ; \mathrm{RI}=0.88$ ). Resolution was very poor, with the strict consensus recovering only two clades within the ingroup, both of them with bootstrap support of $60 \%$ (Fig. 1). The semistrict consensus recovers a few small clades with bootstrap values be low $50 \%$. The successive weighting procedure improved

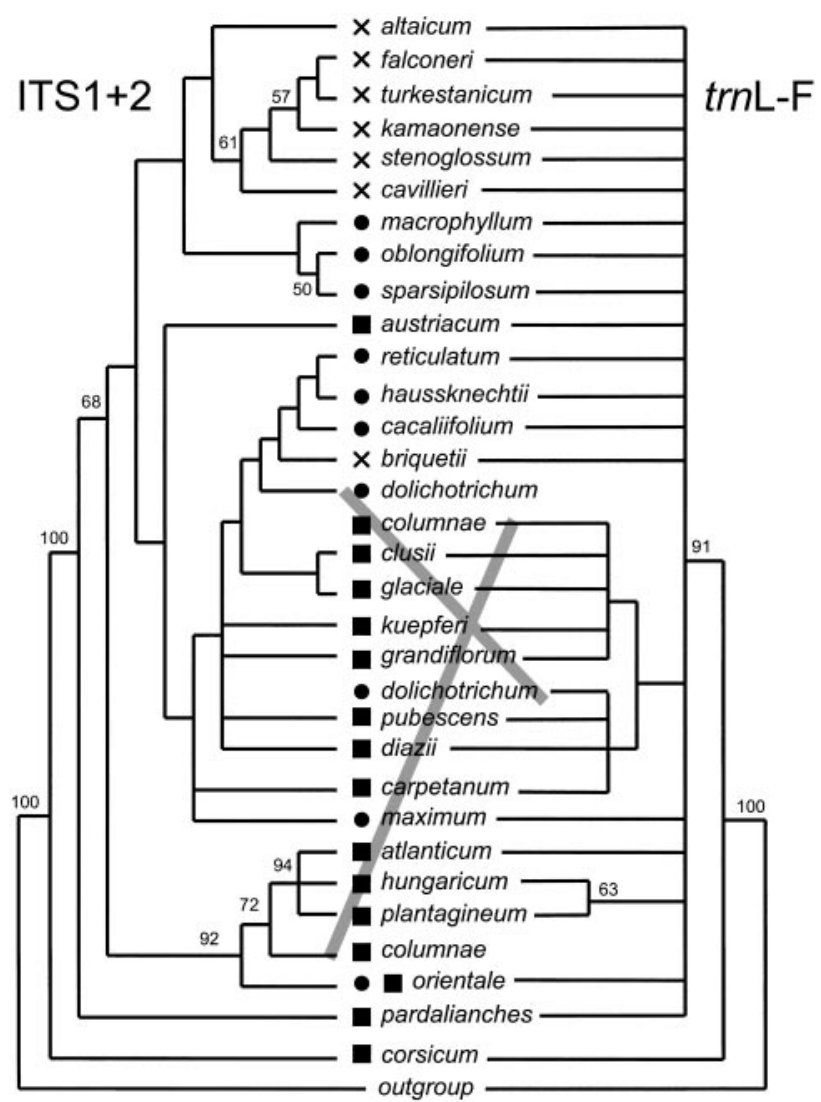

FIG. 2. Congruence between data sets in Doronicum: Comparison of the $50 \%$ majority rule trees from the independent analyses of the internal transcribed spacers (ITS) of the nrDNA and the chloroplast spacer trnL-F. Taxa represented twice to allow comparison of the two trees are linked by gray lines. Bootstrap values above $50 \%$ are shown along the branches. Geographical distribution of the taxa analyzed: central and eastern Asia (crosses), southwest Asia (circles), and Europe and northern Africa (squares).

resolution relative to the original matrix after three rounds, particularly at deeper nodes, and $\mathrm{Cl}$ increased to 0.78 . The clades recovered in the strict consensus of the 52 m.p.t. obtained after those three rounds are incompatible with the topology obtained from the ITS reduced matrix. The only exceptions are two threetaxon clades (D. plantagineum + D. hungaricum + D. atlanticum and D. reticulatum + D. haussknechtii + D. cacaliifolium) appearing in the ITS tree (Fig. 1) compatible with polytomies involving five and seven taxa, respectively, in the morphological successively weighted tree. The increase in $\mathrm{Cl}$ and resolution after successive weighting reveals the importance of homoplasy in the morphological data set (see Discussion).

Combined Data Sets: Congruence Indices and Phylogenetic Analyses

The values obtained in the independent and combined analyses of the three data sets can be seen in Table 3. Consensus from the topologies of the m.p.t. 
TABLE 3

\section{Summary Statistics from the Parsimony Analyses of the Independent and Combined Data Sets for Doronicum}

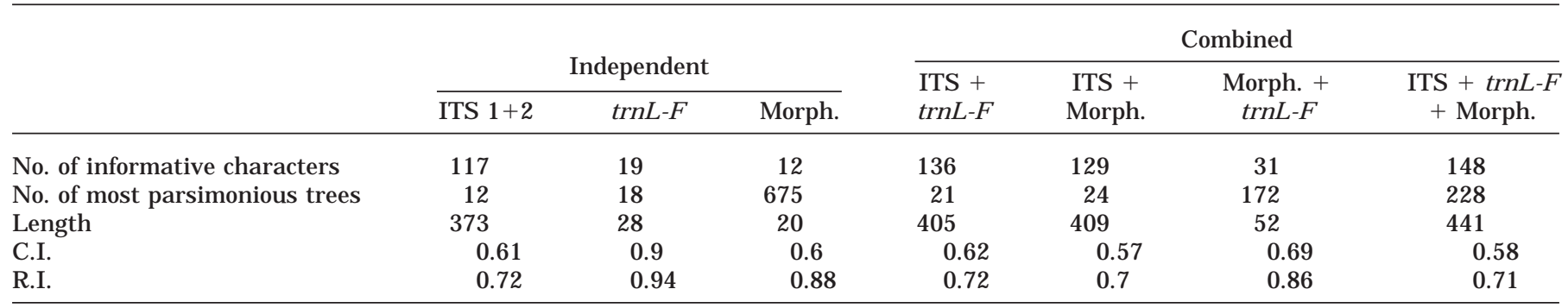

from these analyses can be seen in Fig. 1 to 5 with the exception of the trnL-F + morphology and the ITS + morphology combined data sets.

Comparisons of the topologies of the cladograms resulting from the independent analyses of the three

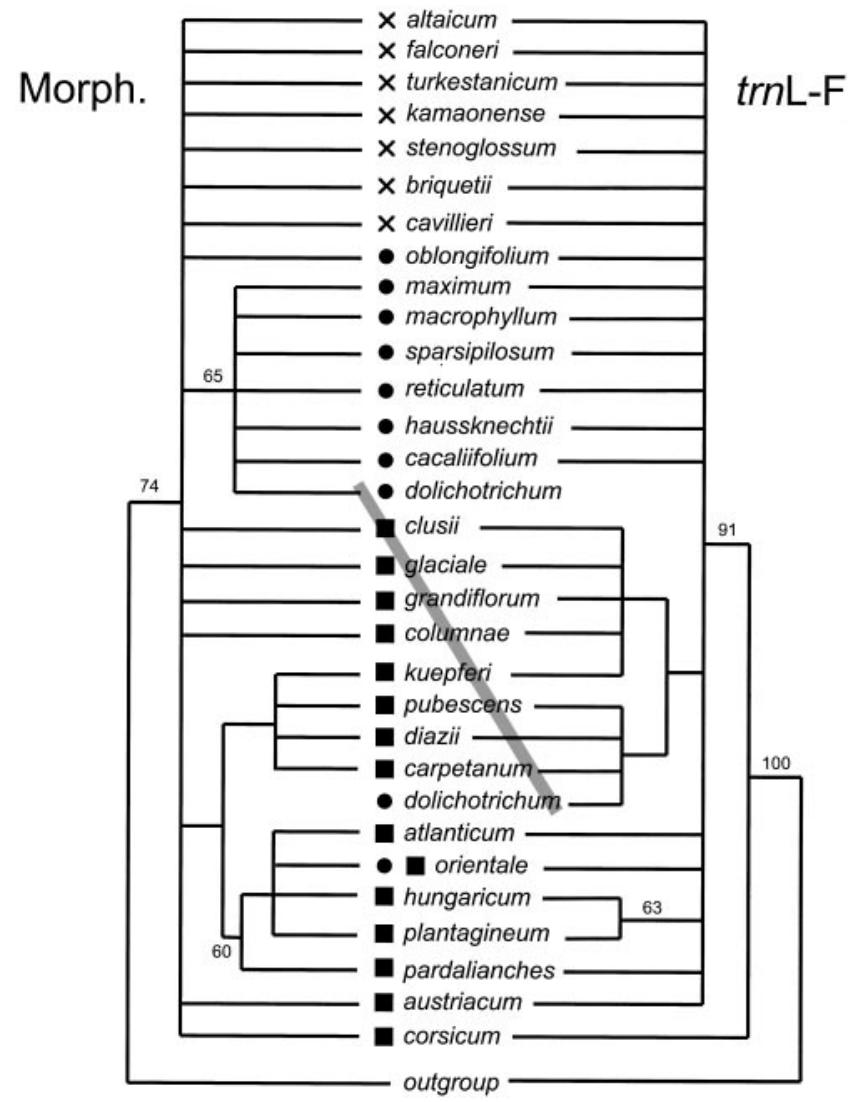

FIG. 3. Congruence between data sets in Doronicum: Comparison of the $50 \%$ majority rule trees from the independent analyses of the chloroplast spacer trnL-F and a morphological data set. A gray line links the only taxon represented twice to allow comparison of the two trees. Bootstrap values above $50 \%$ are shown al ong the branches. Geographical distribution of the taxa analyzed: central and eastern Asia (crosses), southwest Asia (circles), and Europe and northern Africa (squares). data sets do not provide clear agreement (Figs. 1-3). The partition metric is low among trees resulting from the same data set (ITS, trnL-F, or morphology) and rises considerably when trees from different data sets are compared (Table 4). The normalized values between data sets range from 0.31 to 0.75 . Normalized

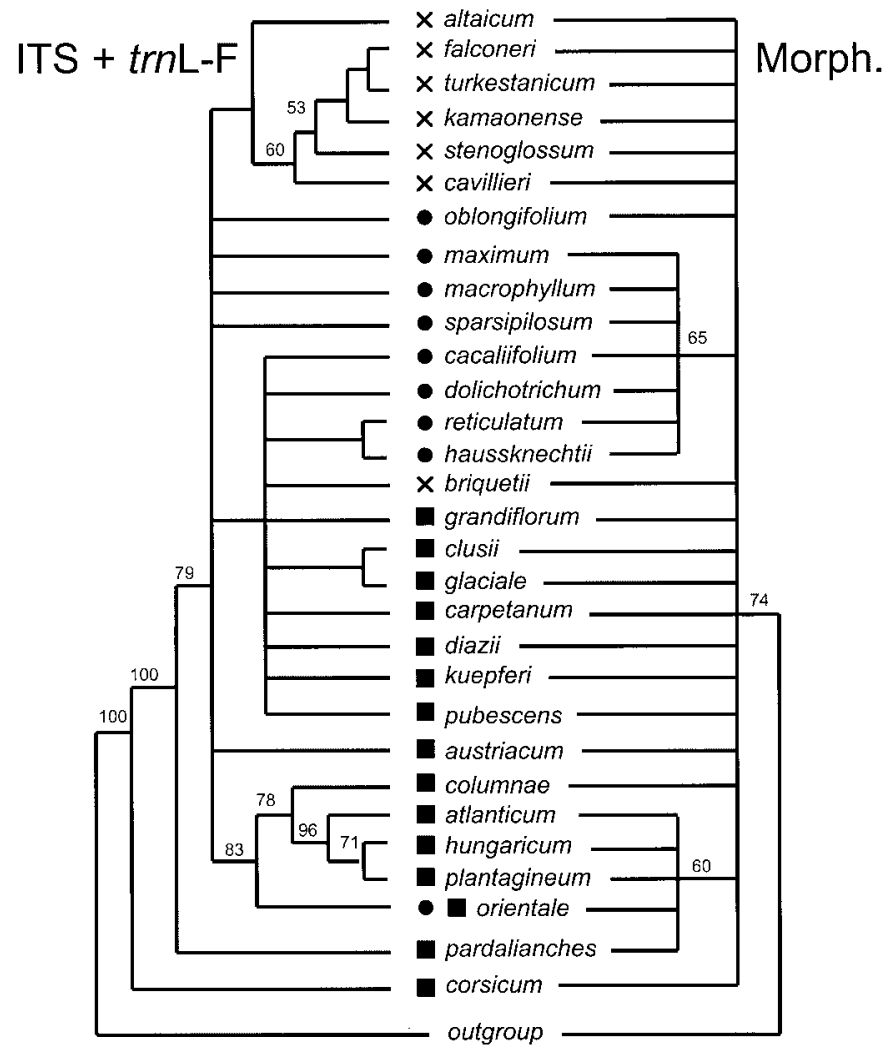

FIG. 4. Congruence between data sets in Doronicum: Comparison of the strict consensus tree from the combined analysis of two molecular data sets (nuclear ribosomal ITS and the chloroplast spacer trnL-F) and the strict consensus from the independent analysis of a morphological data set. Bootstrap values above $50 \%$ are shown along the branches. Geographical distribution of the taxa analyzed: central and eastern Asia (crosses), southwest Asia (circles), and Europe and northern Africa (squares). 

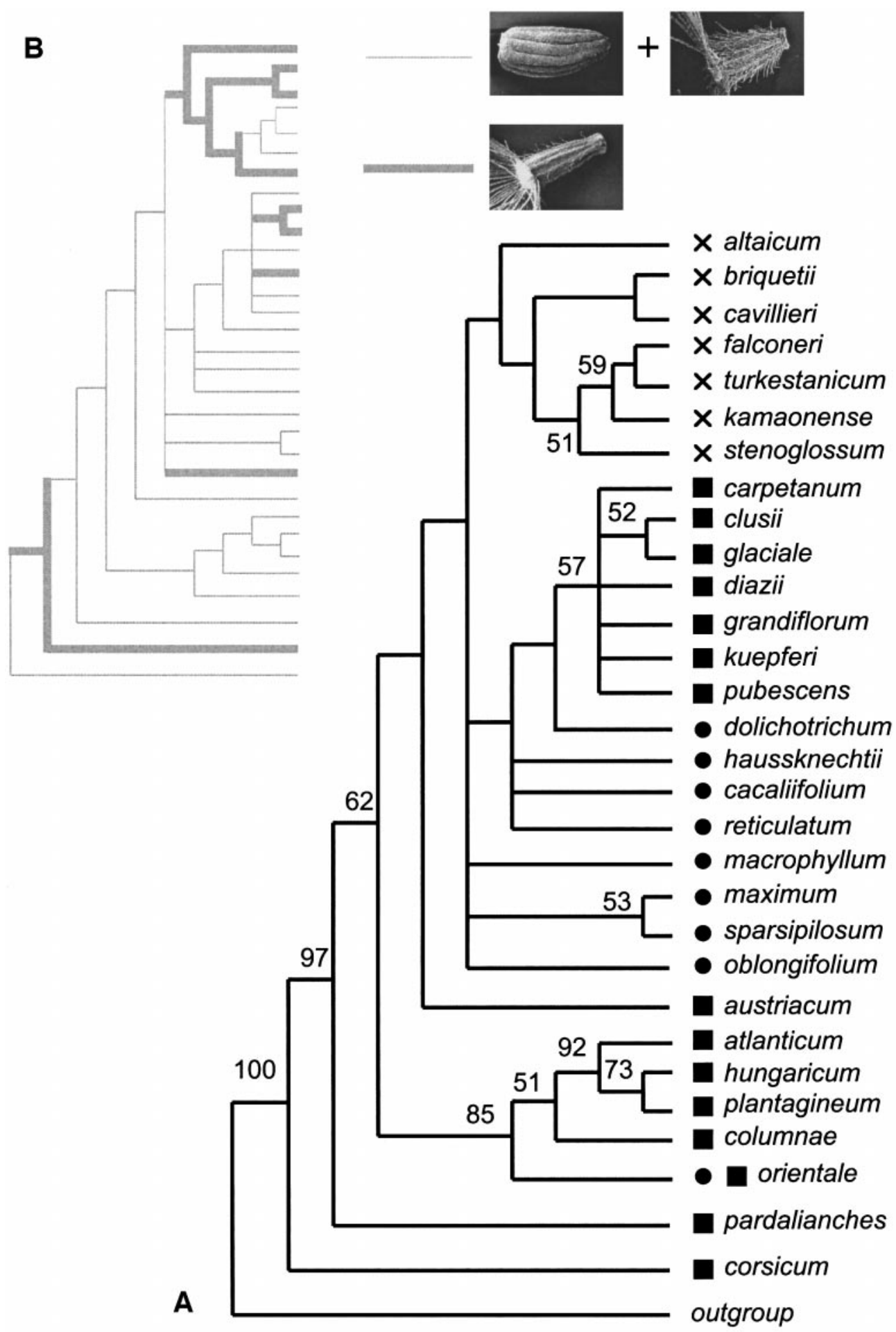

FIG. 5. (A) Strict consensus from 228 most parsimonious trees (length $=441 ; \mathrm{Cl}$, excluding uninformative characters $=0.58$; $\mathrm{RI}=0.71$ ) resulting from the combined analysis of three data sets in Doronicum (morphology, ITS1 +2 , trnL-F). Bootstrap values above $50 \%$ are shown along the branches. Geographical distribution of the taxa analyzed: central and eastern Asia (crosses), southwest Asia (circles), and Europe and northern Africa (squares). (B) Mapping of homocarpy (thick branches) onto the same tree.

values of the greatest agreement subtree metric range from 0.17 to 0.31 , thereby suggesting more incongruence than does the PM.
Of the two character congruence indices, $I_{\mathrm{MF}}$ and $\mathrm{I}_{\mathrm{M}}$, the former is lower than or equal to the latter (Table 4). Both indicate that the most incongruent pair of data 
TABLE 4

Measures of Incongruence between Data Sets for Doronicum

\begin{tabular}{|c|c|c|c|c|c|c|c|}
\hline & & \multicolumn{3}{|c|}{ Within data sets } & \multicolumn{3}{|c|}{ Between data sets } \\
\hline & & ITS & $\operatorname{trnL}-\mathrm{F}$ & Morph. & ITS-trnL-F & ITS-morph. & trnL-F-morph. \\
\hline \multirow[t]{4}{*}{ PM } & Mean & 4 & 4 & 4 & 29 & 37 & 18 \\
\hline & & $(0.93)$ & $(0.93)$ & $(0.93)$ & $(0.50)$ & $(0.36)$ & $(0.69)$ \\
\hline & Range & $1-10$ & $1-8$ & $1-10$ & $26-32$ & $34-40$ & $14-22$ \\
\hline & & $(0.98-0.82)$ & $(0.98-0.86)$ & $(0.98-0.82)$ & $(0.55-0.44)$ & $(0.41-0.31)$ & $(0.75-0.62)$ \\
\hline \multirow[t]{4}{*}{$\mathrm{D}_{1}$} & Mean & 3 & 6 & 5 & 23 & 22 & 22 \\
\hline & & $(0.89)$ & $(0.79)$ & $(0.82)$ & $(0.2)$ & $(0.24)$ & $(0.24)$ \\
\hline & Range & $1-7$ & $1-9$ & $1-9$ & 21-24 & 21-24 & 20-24 \\
\hline & & $(0.96-0.75)$ & $(0.96-0.69)$ & $(0.96-0.69)$ & $(0.27-0.17)$ & $(0.27-0.17)$ & $(0.31-0.17)$ \\
\hline $\mathrm{I}_{\mathrm{MF}}$ & & & & & $4.9 \%$ & $14.1 \%$ & $28.5 \%$ \\
\hline $\mathrm{I}_{\mathrm{M}}$ & & & & & $51.9 \%$ & $50.2 \%$ & $84.8 \%$ \\
\hline $\mathrm{HT}_{\mathrm{F}}$ & & & & & 0.93 & $0.01 *$ & $0.02 *$ \\
\hline
\end{tabular}

Note. Topological congruence indices within and between data sets (partition metric, $\mathrm{PM}$; greatest agreement subtree metric, $\mathrm{D}_{1}$ ), character congruence indices (index of Mickevich and Farris, $I_{M F}$; index of Miyamoto, $I_{M}$ ), and a significance test for heterogeneity of the data sets $\left(\mathrm{HT} \mathrm{F}_{\mathrm{F}}\right.$ ) by Farris et al. (1995). For PM and $\mathrm{D}_{1}$, normalized values are indicated in parentheses (0 less similar, 1 most similar topologies). For $\mathrm{I}_{\mathrm{MF}}$ and $\mathrm{I}_{\mathrm{M}}, 0 \%$ indicates least incongruence and $100 \%$ indicates most incongruence.

sets is morphology/trnL-F and the most congruent is ITS/trnL-F. This result implies that the morphological matrix, containing a number of informative characters more than nine times smaller than that of the ITS matrix, is the most heterogeneous data set of the three.

The significance test for heterogeneity, based on the incongruence length difference of Mickevich and Farris (1981), rejects the null hypothesis of homogeneity between data sets in the two pairs in which the morphological data are involved (morphology/lTS and morphology/trnL-F). This test thus confirms that the morphological data are discordant with the two molecular data sets.

\section{Placement of Doronicum within Senecioneae}

The parsimony analysis of ndhF in a sample of Asteraceae resulted in 4600 optimal trees (length $=2447$; $\mathrm{Cl}$, excluding autapomorphic characters $=0.44$; $\mathrm{RI}=$ 0.56). The topology of the strict consensus is the same as that obtained by Kim and J ansen (1995) (Fig. 6). The five genera bel onging in the Senecioneae (Senecio, Lopholaena, Blennosperma, Syneilesis, and Doronicum) form a monophyletic group, although the bootstrap support is not strong. Topological relationships within the clade are identical in all the optimal trees. Doronicum is sister to the other four genera.

\section{DISCUSSION}

\section{ITS Variability and Intraspecific Sampling}

The ITS region is considerably variable within Doronicum (55 parsimony-informative characters), implying favorable signal for reconstruction of interspecific relationships. The size of ITS1 in Doronicum is within the limits reported by Baldwin et al. (1995) for Asteraceae. ITS2 is 6 bp shorter but clearly within the ranges determined by more recent work in Asteraceae (Susanna et al., 1995; Kim et al., 1996, 1999; FranciscoOrtega et al., 1997, 1999; Kornkoven et al., 1998; Panero et al., 1999; Torrell et al., 1999).

Although our sampling does not allow comprehen-

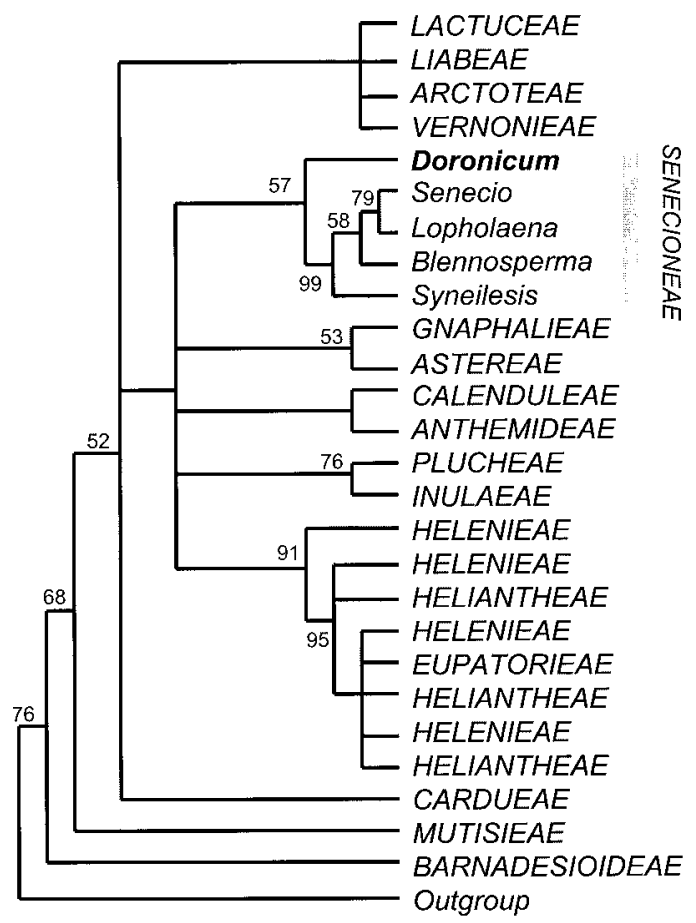

FIG. 6. Abbreviated strict consensus from 4600 most parsimonious trees resulting from the analysis of the chloroplast gene ndhF in a sample of the Asteraceae (59 terminal taxa, length $=2447 ; \mathrm{Cl}$, excluding uninformative characters $=0.44 ; \mathrm{RI}=0.56$ ). Bootstrap values above $50 \%$ are shown along the branches. The data matrix is a subset of that in Kim and J ansen (1995) to which a sequence from Doronicum has been added. 
sive assessment of the intraspecific level of ITS variation, some conclusions can be drawn. The main question is whether or not intraspecific variation is sufficient, given limited sampling (the rule in systematically and phylogenetically oriented studies), to cause errors in reconstructing the species phylogeny. We cannot exclude this possibility for certain taxa, mostly Asian, that are included in unresolved clades and for which only one sequence is available. Neverthel ess, such a possibility is minimized in those species for which we have more than one molecular sample, once the intraspecific variation detected in them and its effects are examined.

In our study, more than 1 sequence per species or subspecies was obtained for six different taxa. This sampling resulted in 12 additional sequences, mostly from Europe, included in only the separate analyses of ITS1 and ITS2. The intrataxon variability detected in those sequences does not have serious effects on the analysis. When the results of the analysis of the ITS1 + ITS2 reduced matrix are compared to the independent analyses of the ITS1 and ITS2 extended matrices, the number of m.p.t. drops dramatically (12 vs 1492 and 1118, respectively). However, the reason for improvement in resolution and reduction in number of optimal trees is not the removal of conflicting variation at the intraspecific level. When ITS1 and ITS2 are separately analyzed under parsimony with only one sample per species, i.e., by removal of the additional sequences for each taxon (trees not shown), the number of trees dropped to half for ITS2 (516 vs 1118) but increased more than sixfold for ITS1 (9522 vS 1492). F urther, the C.I . not only did not increase as one might expect from reduction of the number of terminals in a parsimony analysis (Sanderson and Donoghue, 1996), but it dropped slightly for ITS1 (0.65 vS 0.68 ) and did not change for ITS2 (0.71). U nambiguous resolution remained as poor as that obtained from the analysis of intact extended ITS1 and ITS2 matrices.

In two of the six taxa for which we have more than one sequence, polyploid populations are known: D. pardalianches and D. plantagineum. Therefore, these two species would be candidates to contain intraspecific variability for ITS sequences. However, sequence distances within each of these two species are not noteworthy. More importantly, the two sequences from D. pardalianches and the five from $\mathrm{D}$. plantagineum cluster in their own respective clades. This suggests that intraspecific variability does not interfere with variation that is informative (phylogenetic signal) at the species level. Neither the four sequences of D. grandiflorum nor the three sequences of $D$. carpetanum subsp. kuepferi form exclusive clades in the strict consensus tree from the analyses of the ITS1 and ITS2 extended matrices. However, this apparent lack of monophyly is not due to differences among the se quences (e.g., those from kuepferi are identical), but is due to lack of characters that are exclusive to either taxa, i.e., synapomorphies for D. grandiflorum or for D. carpetanum subsp. kuepferi. A similar situation is found in D. falconeri. The sample included from Xinjiang (China) under the synonym $D$. turkestanicum in the ITS reduced matrix is almost identical to the other sample from Pakistan (distances: 0 in ITS1, 0.009 in ITS2, 0 in trnL-F). The two ITS sequences cluster in a clade in most of the analyses, a result that supports our taxonomy and provides another example of very low intraspecific ITS polymorphism within Doronicum.

The greatest divergence found in this study between sequences of the same species occurs in D. austriacum. The two sequences, from Greece and Poland, differ by 11 nucleotide substitutions (6 in ITS1 and 5 in ITS2), of which only 2 are autapomorphic. However, 4 of the remaining 9 differences correspond to nucleotides (sites 6, 50, 308, and 423) that do not show a characterstate distribution consistent either with geography or with taxonomically recognizable groups and are thus likely to be highly variable positions. Not evidently noisy positions include 130, for which the Greek sample of D. austriacum (but not the Polish sample) shares an " $A$ " with the $D$. plantagineum group, D. macrophyllum and its allies, D. carpetanum, D. carpaticum, and two additional southwestern Asian taxa (D. macrolepis and D. maximum) (Appendix 1). As a whole, there is not a clear pattern that could suggest differentiation or hybridization as the cause behind those differences between the samples of $D$. austriacum. Moreover, both sequences form a clade when the Polish sample is added to the ITS1 + ITS2 reduced matrix (tree not shown). We conclude that the intraspecific variability detected in our study that is not autapomorphic seems to be homoplastic. Therefore intraspecific differences do not question the potential informativeness of ITS variation in reconstructing the species phylogeny because sequences from the same species either form exclusive clades or, if lacking synapomorphies, cluster in the same clade with other terminals.

The four subspecies recognized within D. carpetanum (subsp. carpetanum, diazii, kuepferi, and pubescens) are not monophyletic but they nest in a clade containing other species in the molecular, morphological, and total evidence trees (Figs. 1, 4, and 5). D. macrophyllum subsp. sparsipilosum exhibits slight morphological differences (fewer cauline leaves and capitula) from subsp. macrophyllum. Results from our ITS analysis show, however, that subsp. sparsi pil osum is not sister to subsp. macrophyllum but is instead sister to D. oblongifolium (Fig. 1), and if all evidence is used, subsp. sparsipilosum is sister to D. maximum (Fig. 5). The latter result has weak support (Fig. 5). Divergence between the ITS sequences of the two subspecies is 0.032 in ITS1 and 0.024 in ITS2. Another potential case of conflict is represented by the northern African populations described under D. atlanticum, a 
taxon that we have kept in the analyses despite the lack of consistent morphological features to differentiate it from $D$. plantagineum. The divergences between D. atlanticum and the five sequences of D. plantagineum range from 0.027 to 0.035 in ITS1 and from 0.019 to 0.034 in ITS2. Whereas the samples bel onging to D. plantagineum are nested together and form a monophyletic group in both the separate ITS1 and ITS2 trees (trees not shown), the ITS1 and ITS2 sequences of $D$. atlanticum fell out of the five-sequence plantagineum clade as did D. hungaricum. The possibility exists that the apparent contradictory placement of these species as not sister to each other is the result of sampling error, introgression, or the possibility that the northern African populations of D. atlanticum should be regarded as a different species.

The latter two cases are the only cases revealing intraspecific ITS variability that might suggest problems when trying to infer organismic phylogeny from gene trees. However, in both cases underlying taxonomic issues may be responsible for the apparent contradictory placements of different samples from the same species. That is, the differences in ITS sequences between $D$. atlanticum and $D$. plantagineum may be relevant at the species-level phylogeny even though morphological differentiation is poor. Taxonomic treatment that would turn this "intraspecific" ITS variability into interspecific variation might be justified. Alternatively, sequence differences might be due to introgression from D. orientale, which would have implications for the species phylogeny but might not demand taxonomic adjustments. Further sampling is therefore required to determine the most likely reason for those two discordant cases. In all, it seems that informativeness of ITS data for reconstructing the phylogeny of the genus is not precluded by intraspecific variability coupled with sampling error.

\section{Combined and Independent Analyses}

Theoretical issues aside, a combined (total evidence) analysis improves the opportunity to detect phylogenetic signal amid background noise by increasing the number of characters (Soltis et al., 1998). On the other hand, analysis of different data sets separately allows the identification of serious heterogeneity that would otherwise contribute additional noise and thus might override the true phylogenetic signal. A justification for the third (conditional combination) approach is that it attempts to reduce the risk of mixing different signals, which is another source of noise in addition to homoplasy. However, arriving at the conclusion that two data partitions are incongruent does not mean that they are both equally reliable. The following argument is in the spirit of Wendel and Doyle's (1998) contention that incongruence between data sets need not be perceived as negative results, since they may be indicators of previously unsuspected biological processes. A seri- ous incongruence between two data sets allows more than the mere questioning of their merging into a single data matrix for analysis. In Doronicum, we claim that even such questioning may be reconsidered in favor of a total evidence approach when all the evidence about characters, analyses, etc. is taken into account.

Given the results of the significance test for heterogeneity, an application of the conditional combination approach (Bull et al., 1993) in Doronicum would suggest that we combine only the ITS and trnL-F data into a single matrix. The morphology should be analyzed independently and the results of the two analyses compared for common clades. However, when we look for common clades in the strict consensus of the analyses of molecular and morphological data (Fig. 4), we find that there are none within the ingroup, although there are some minor clades that are compatible with the alternative topology. A strict application of this procedure would leave us without a single component of information supported by the three data sets. This result appears to be too radical, particularly given that the discrepancies between data sets do not seem to be strongly supported by each data set and thus suggest an insightful biological alternative explanation (Wendel and Doyle, 1998). We believe that following the conditional combination approach leads, in these specific data sets, to some kind of reductio ad absurdum.

Reasons for disagreement between molecular trees and species trees have been described elsewhere (Doyle, 1992, 1997; Maddison, 1997). Because some of them involve molecular mechanisms (gene duplication, lineage sorting), we might suspect that the molecular tree (based on the ITS + trnL-F data matrices) could be a worse representation of the species phylogeny than the morphological tree. However, it seems that such is not the case. Despite the fact that ITS is inherited biparentally and trnL-F is inherited maternally, these two data sets are homogeneous. The most likely explanation for the branching histories of the two molecular markers agreeing despite their differences in inheritance and relevant mechanisms (recombination, concerted evolution, etc.) is that they are a good reflection of the species branching pattern. In addition, the summary statistics resulting from the parsimony analysis of the morphological data set are clearly worse than those from the combined mol ecular data set. The C.I I is similar (0.62) even though the number of informative characters is 11 times greater in the molecular data, and the bootstrap support for most groups is lower in the morphological trees, as is the resolution. In contrast, the number of m.p.t. is much higher in the morphological analyses (675 vs 21). Therefore, although morphological characters are few, they contain a considerable amount of incongruence among themselves, probably the result of errors in homology assessment (primary homology sensu de Pinna, 1991). These mor- 
phological characters seem to contain poor recoverable signal for the reconstruction of species phylogeny despite the fact that a detailed morphological study has been conducted on the basis of more than 4000 herbarium specimens. The fact that after three rounds of successive weighting, the clades obtained are incompatible with those from the ITS tree seems to provide support for our interpretation that the morphological data set contains an excess of incorrect homology assessments.

Based on the above argument, either we could rely exclusively on the phylogenetic hypothesis based on the molecular matrix and disregard the morphological matrix or we could merge all the data together into a single (total evidence) matrix (Fig. 5). The first solution produces slightly better parameters in the number of m.p.t. (Table 3) but discarding a set of empirical data seems difficult to justify epistemologically, even if we map the morphological characters a posteriori on the molecular trees. In contrast, the combined analysis of the three data sets constitutes a homology test for the morphological characters against the molecular characters (Patterson, 1988). In fact, the most stringent homology test for a set of characters is to analyze it together with other characters to see which patterns are reinforced and which are questioned by congruence. The results of such a test can be read on the resulting cladograms generated from the parsimony analysis of the combined matrix. There is an additional justification for letting other sets of (in this case molecular) characters decide which of the morphological characters contain more noise in reconstructing the species phylogeny: the low number of morphological characters. Provided that the molecular data set appears to convey more phylogenetic signal for reconstructing the species phylogeny, if we were to merge the molecular data together with a high number of morphological characters containing much homoplasy, the true phylogenetic signal might be partially overridden. Thus, the low number of morphological characters is, in this case, appropriate for preferring the total evidence approach and performing the congruence test.

The results of the combined analysis show that 7 of the 12 morphological characters require high amounts of homoplasy to be optimized in the m.p.t. Therefore, their coding as the same character is not confirmed by the parsimony analysis and instead seems to result from incorrect homology assessment (primary homology). In particular, the occurrence of two types of fruit within a single inflorescence (heterocarpy) is not uncommon within groups of Asteraceae (Zohary, 1950). Although it has ecological significance for dispersal and germination and the shift from heterocarpy to homocarpy is frequent (Venable and Levin, 1985; I mbert et al., 1996), in Doroni cum this character has been considered of taxonomic importance even at the generic level (Candolle, 1838; Cavillier, 1907, 1911). The fact that homocarpy requires five independent gains (seven steps) to be optimized on the m.p.t. indicates that it fails to pass a test of homology by congruence with the rest of the characters (Fig. 5). A similar case is that of the presence of hairs (six steps) and buds (seven steps) in the rhizome, as well as the shape of the internodes in the rhizome (four steps), and the pinnate-reticulate leaf venation (five steps), the architecture of the D. macrophyllum group (four steps), and the occurrence of glands in the cypselae (five steps). The 5 remaining morphological characters require one step and thus contain no homoplasy.

\section{Systematic and Biogeographic I mplications}

We consider that the best estimate of phylogenetic relationships within Doronicum is that which is obtained from the combined analysis of the three data sets (Fig. 5). This analysis allows a number of wellsupported conclusions and suggestions.

Doronicum is monophyletic in all the analyses that we have conducted. This is consistent irrespective of which data set or combination of them is used. In all analyses, except the morphological, bootstrap support for the Doronicum clade is $100 \%$, and our sampling of the genus in terms of species is comprehensive $(100 \%$ of the species in the ITS extended matrices, $92 \%$ in the ITS reduced matrix and in the trnL-F matrix). It can be argued that the outgroup taxa are too far removed to test the monophyly of the genus. However, we lack information as to which other genus could be the immediate sister taxon of Doroni cum. Doroni cum has not been included in any of the most comprehensive molecular studies for the tribe to date (Kadereit and J effrey, 1996; Knox, 1996; Kim and J ansen, 1995). Historically, the Chinese endemic genus Nannogl ottis has been allied to Doronicum. In fact, N. hookeri was included in Doronicum by Cavillier $(1907,1911)$ but placed in its own section. The placement of Nannoglottis within Senecioneae is not supported based on the morphology of reproductive features such as the stylar branches (Nordenstam, 1977). We follow Bremer (1994) who includes the genus within tribe Astereae. Attempts to isolate and amplify DNA of $\mathrm{N}$. hookeri have been unsuccessful. D. stenogl ossum was placed in a monotypic section created by Cavillier (1911). Morphological features separating $D$. stenoglossum from the rest of the species are all autapomorphic (e.g., the linear greenish ligules or the arrangement and structure of the pappus) and thus we believe that it should be classified with its sister species. In all our analyses D. stenoglossum is always deeply nested within Doronicum.

The most outstanding result of this study is the basal position of $\mathrm{D}$. corsicum, sister to the remaining species, a result that has strong biogeographic implications (Fig. 5). Based on our study, the evolution of Doronicum appears to have foll owed successive splitting lead- 


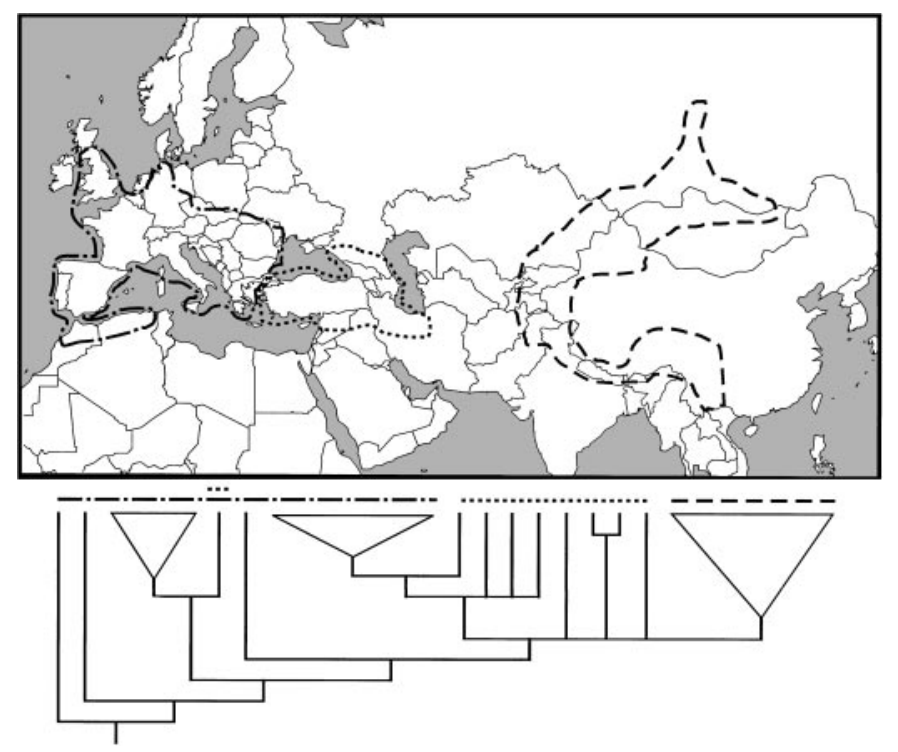

FIG. 7. Correspondence between the geographic distribution of the species of Doronicum and the strict consensus tree from the combined analysis of the three data sets shown in Fig. 5.

ing to the European species D. pardalianches and the D. plantagi neum clade. These species are mostly Mediterranean in distribution, except for D. hungaricum (eastern European). Therefore, it appears that an early diversification took place on the European continent, or more specifically, in the Mediterranean basin (Fig. 7).

The core species of the D. plantagineum group (D. plantagineum, D. atlanticum, D. hungaricum, D. orientale) share a number of morphological characters that are the most congruent with the molecular data. These characters include the scapiform habit (few reduced cauline leaves), triplinerved leaf venation, and ciliate involucral bracts. The species belonging to this group occur in areas dominated by Mediterranean forests. However, the inclusion of D. columnae, which usually occurs at higher elevations, is uncertain despite the high support for the clade. Morphologically, the scapiform habit in D. col umnaeis clearly consistent with that of the other species, the leaf venation is slightly different, and the involucral cilia are present, although not in every population. Furthermore, the position of $D$. columnae in the ITS trees, nested within the D. plantagineum group, differs from that in the trnL-F trees (Fig. 2). The different placement of $D$. col umnae in the two gene trees and its partial morphological affinity with the $D$. plantagineum group suggest a possible hybrid origin.

Another group that tends to appear in the cladograms of the various analyses, although with low bootstrap support in the total evidence analysis (47\%), includes central and eastern Asian taxa. Of these taxa, the placement of $\mathrm{D}$. briqueti i is equivocal, nested in a clade with taxa from southwestern Asia in the ITS tree (Fig. 5).
The clade containing D. grandiflorum, although weakly supported ( $57 \%$ bootstrap), includes a group of species that share similar ecological requirements and parapatric distributions. The D. grandiflorum clade contains D. grandiflorum (from the eastern Alps to the Cantabrian mountains in northern Spain), its close relatives D. glaciale (Alps) and D. clusii (Alps and Carpathians), and four cl osely related I berian taxa (the four subspecies of D. carpetanum, subsp. carpetanum, kuepferi, pubescens, and diazii). All of them occur on mountain habitats and exhibit a fleshy rhizome with minute hairs on the nodes.

Cavillier (1911) recognized subsection Macrophylla which includes species from Turkey, the Caucasus, and the Caspian area (D. cacaliifolium, D. dolichotrichum, D. haussknechtii, D. macrophyllum, D. maximum, D. reticulatum). Morphologically, all species share a growth habit typical of al pine European plants growing on rich, humid soils receiving large amounts of snow, namely, tall herbs with a few very large reticulately veined leaves with several to many capitula. The molecular data, however, do not support the recognition of this group. The above-mentioned European diversification is supported by four subsequent basal nodes ending in European terminals in the strict consensus tree (Fig. 5). The rest of the inferred cladogenetic events may roughly conform to a west- east sequence (Fig. 7). However, any conclusion beyond those four basal nodes is tentative because either bootstrap support is low or resolution is poor. In fact, in the remaining portion of the tree, a European clade (D. grandiflorum, D. glaciale, D. clusii, D. carpetanum) occurs distally to several southwestern Asian species. In all, the geographic structure of the tree seems noticeable because the only species occurring on two of the three large areas marked in Fig. 7 is D. orientale. Such a structure does not answer the question of whether the geographic structure has been shaped mainly by vicariance or by dispersal events.

\section{Placement of Doronicum}

The Senecioneae is the largest tribe in the Asteraceae, with 3200 species and approximately 120 genera (Bremer, 1994). The placement of Doronicum within the Senecioneae was proposed by Cassini (1819) and subsequently accepted by Bentham and Hooker (18731876). In addition, Doronicum shares with other Senecioneae a basic chromosome number (probably secondary) of $\mathrm{x}=30$ and pyrrolizidine alkal oids (N ordenstam, 1977; J effrey, 1987; Bremer, 1994). The few molecular studies that have sampled Senecioneae species did not include Doronicum (J ansen et al., 1990, 1991; Kim et al., 1992; Kim and J ansen, 1995; Knox 1996; Kadereit and J effrey, 1996), and thus, the present study addresses for the first time the position of this genus on the basis of molecular evidence.

Phylogenetic analyses of ndhF sequence data reveal 
that Doronicum is a member of tribe Senecioneae (Fig. 6). The position of Doronicum as sister to a clade containing the genera Blennosperma, Lopholaena, Senecio, and Syneilesis contradicts the widely held assumption that members of the Blennospermatinae (here represented by Blennosperma) are the basal group of the Senecioneae (Bremer, 1994 and other references therein). Despite the weak sampling, it is important to note that the four other genera form a strongly sup- ported clade (bootstrap 99\%), with the sister position of Doronicum being weakly supported (bootstrap 57\%). These results lead to speculation that the widely held phylogenetic assumptions about the relationships of the Senecioneae are at best controversial and may prove incorrect once more extensive studies are completed. In sum, our analysis using ndhF data provides support, albeit not conclusive, for the placement of Doronicum within tribe Senecioneae. 


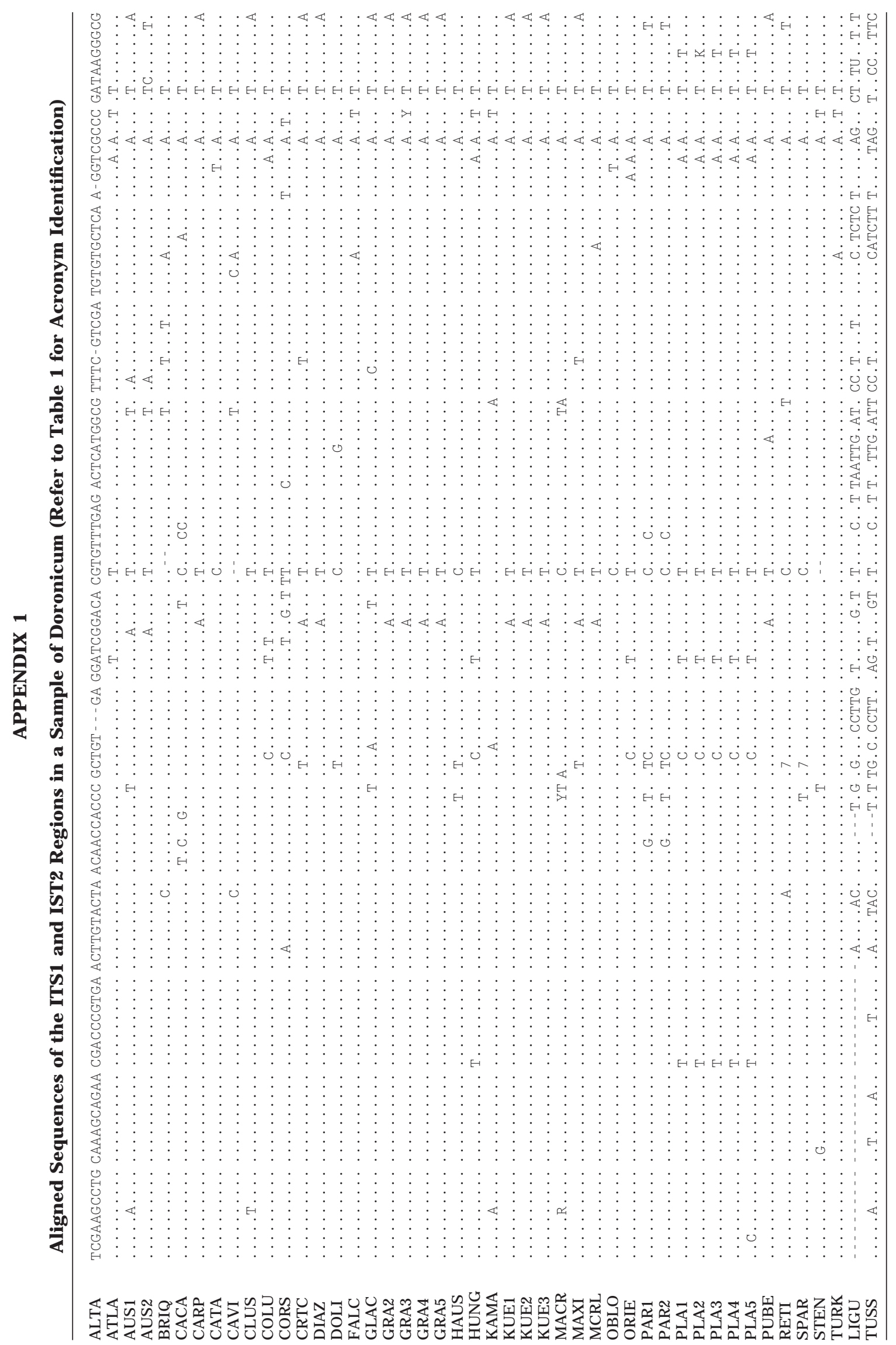




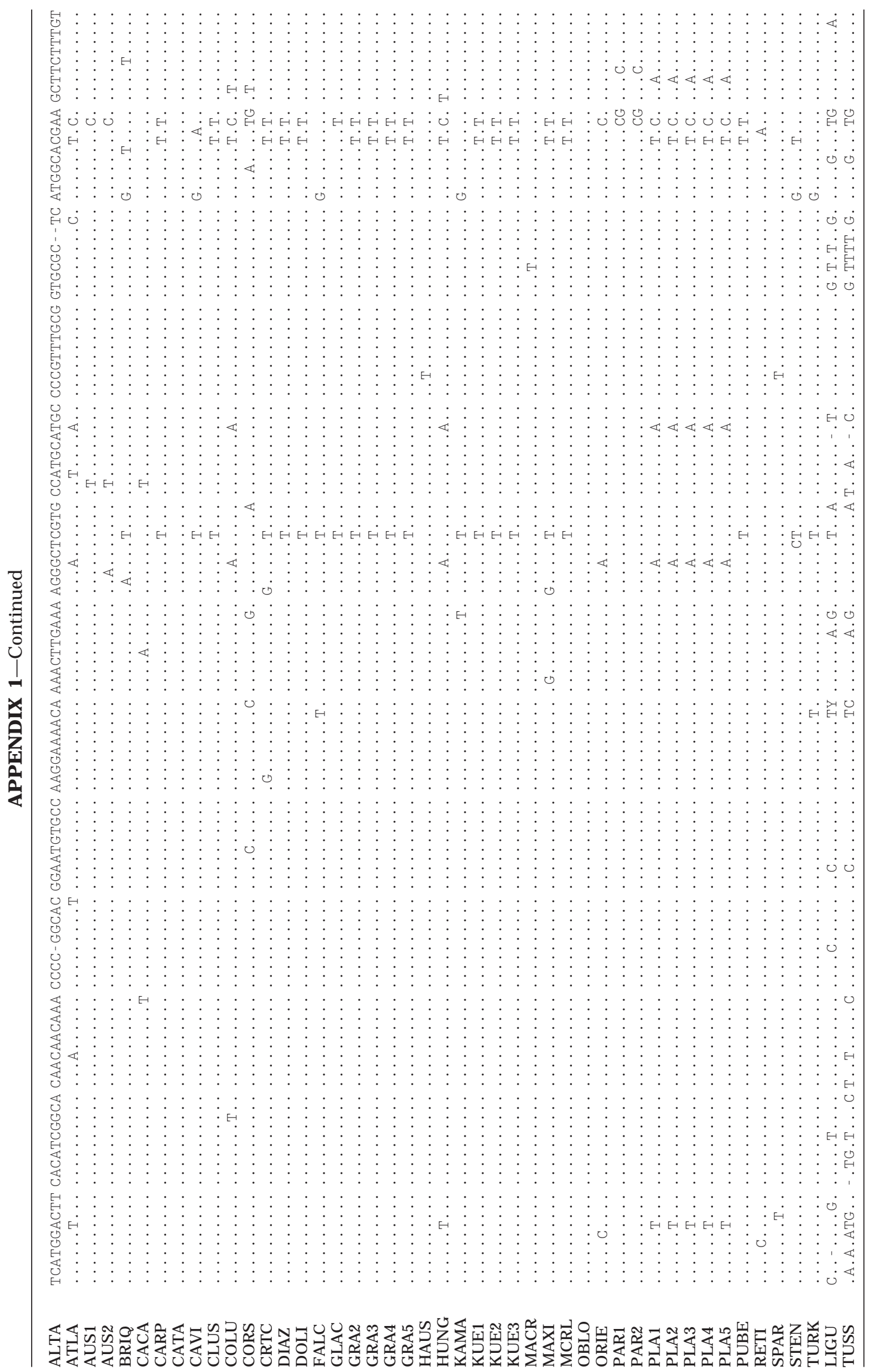




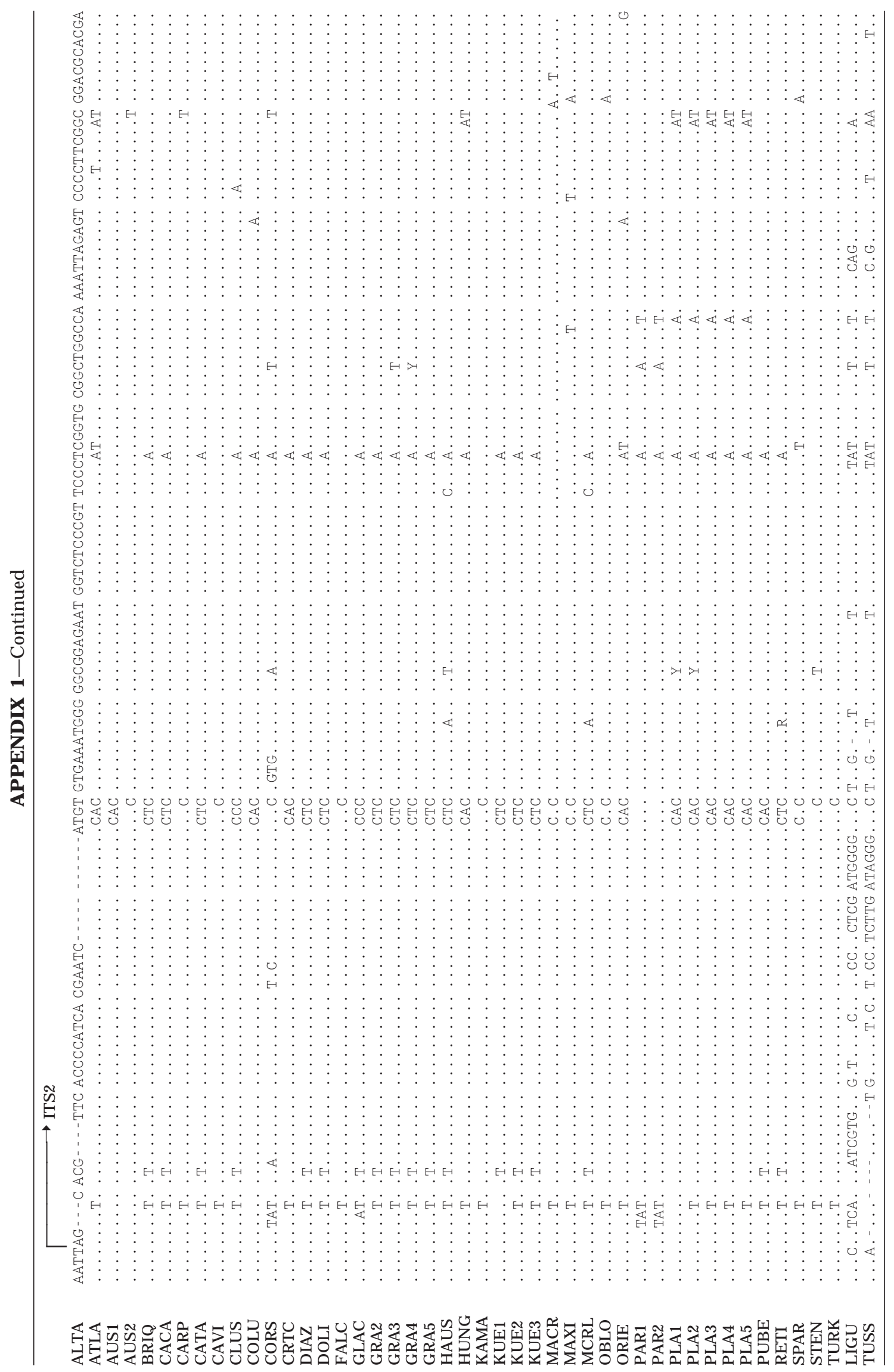




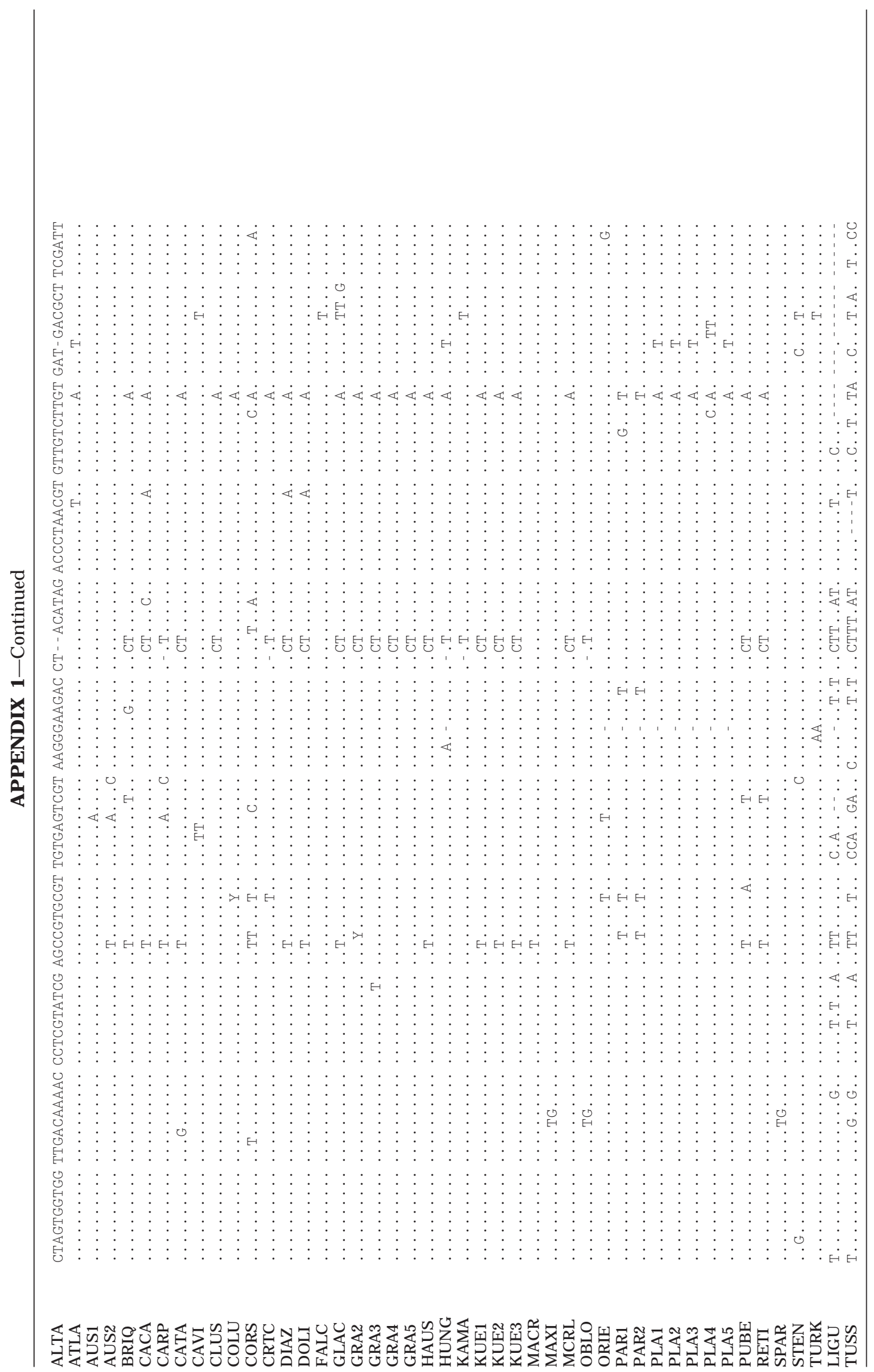




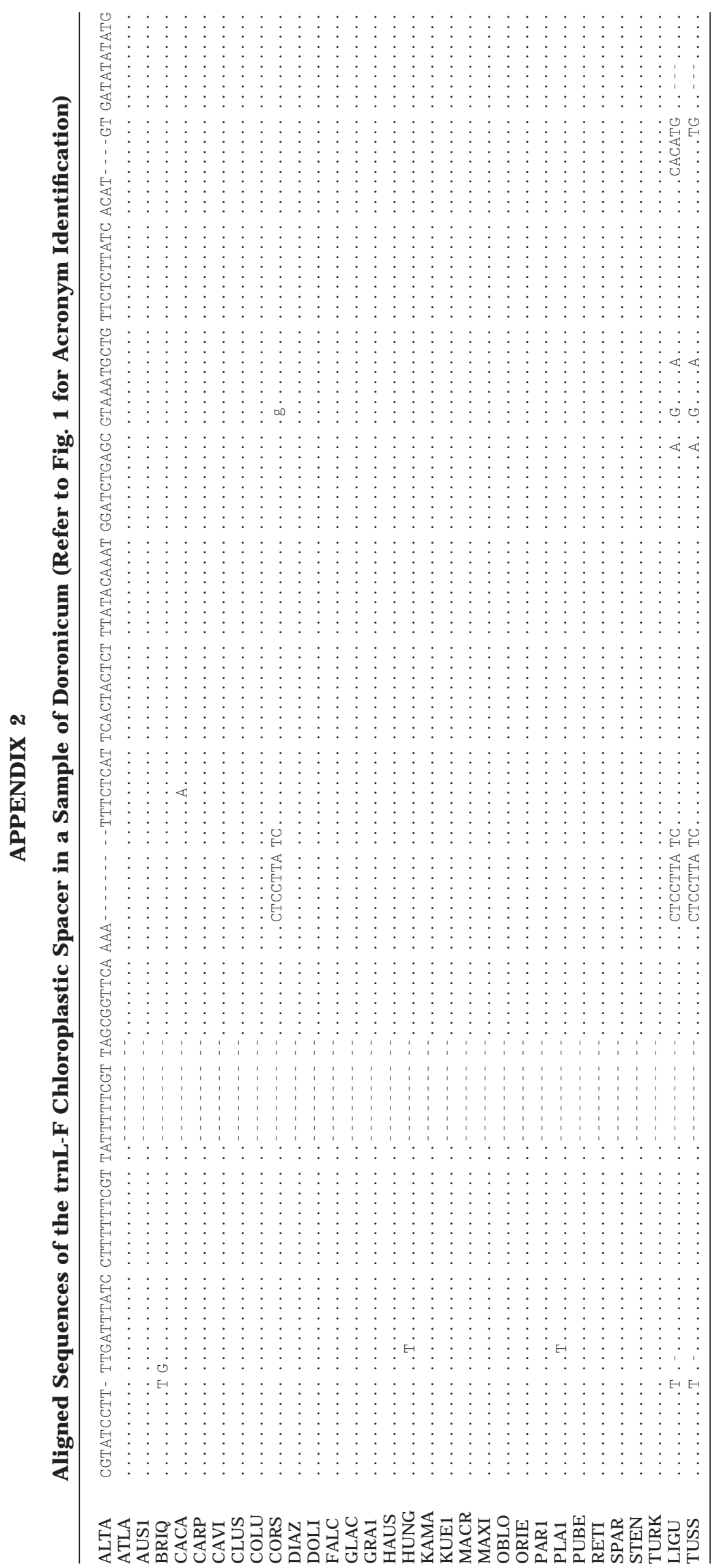




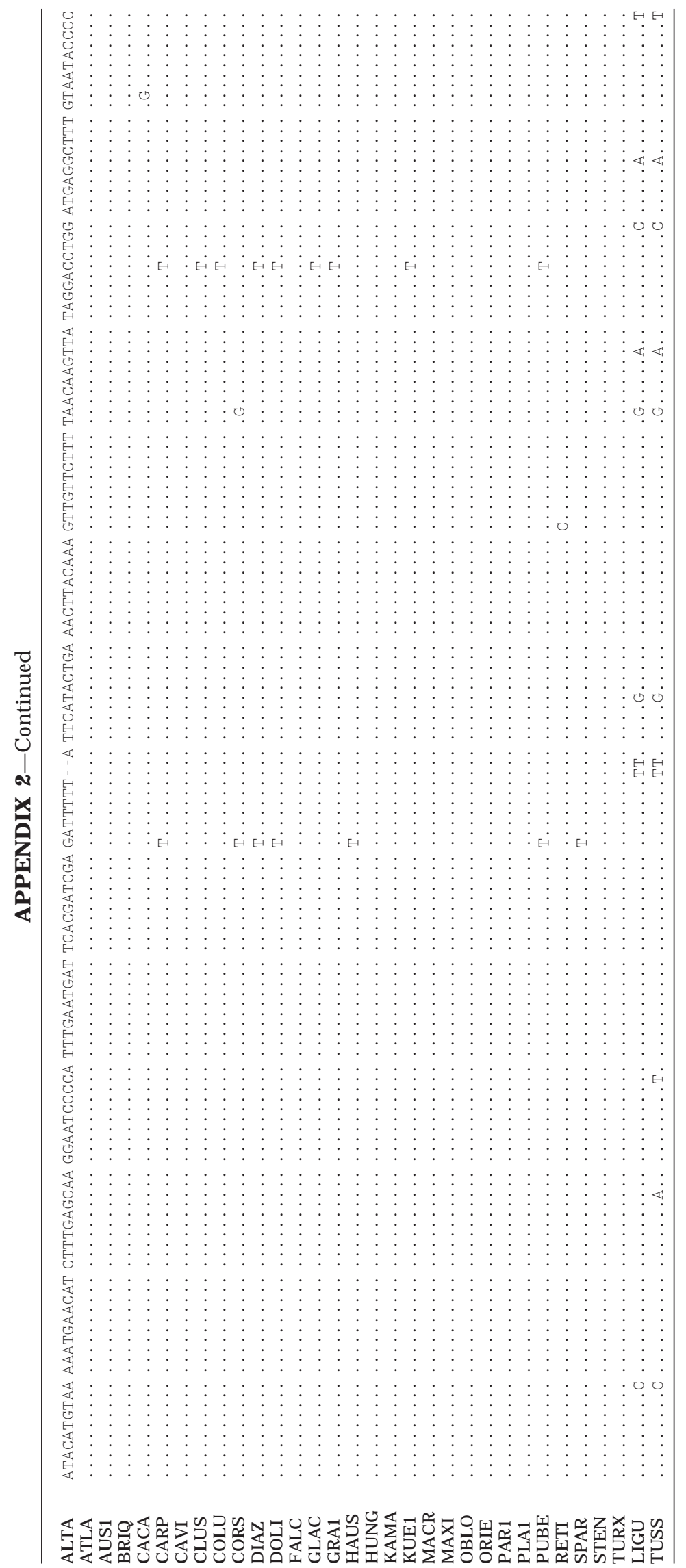




\section{ACKN O WLEDGMENTS}

We are grateful to J . Francisco-Ortega and P. Vargas for constructive comments on our manuscript, to S. Castroviejo, M. A. García, A. Herrero, M. Martínez, L. Medina, and P. Pérez for supplying plant material, and to R. K. J ansen for kindly providing the data matrix of ndhF sequences of Asteraceae. This work has been supported by Grant DGES PB96-0849 of the Spanish Dirección General de Enseñanza Superior e Investigación Científica.

\section{REFERENCES}

Avetisyan, V. E. (1980). Rod Doronicum L. v Armenii (Doronicum L. genus in Armenia). Biol. Z. Armenii 33: 532-534.

Bentham, G., and Hooker, J . D. (1873-1876). "Genera Plantarum," Vol. 2, Reeve, London.

Bremer, K. (1994). “Asteraceae: Cladistics \& Classification," Timber Press, Portland, OR.

Bull, J. J ., Huelsenbeck, J . P., Cunningham, C. W., Swofford, D. L., and Waddell, P. J. (1993). Partitioning and combining data in phylogenetic analysis. Syst. Biol. 42: 384-397.

Candolle, A. P. De (1838). "Prodromus Systematis Naturalis Regni Vegetabilis," Vol. 6, Treuttel \& Würtz, Paris.

Cassini, H. (1819). Suite du sixème mémoire sur la famille des synanthérées. J . Phys. Chim. Hist. Nat. Arts 88: 189-204.

Cavillier, F . (1907). Étude sur les Doronicum à fruits homomorphes. Annu. Conserv. J ard. Bot. Genève 10: 177-251.

Cavillier, F. (1911). Nouvelles études sur le genre Doronicum. Annu. Conserv. J ard. Bot. Genève 13-14: 195-368.

Chacón, R. (1987). Contribución al estudio taxonómico del género Doronicum L. (Compositae) en Ia Península I bérica. Anal. J ard. Bot. Madrid 43: 253-270.

De Queiroz, A., Donoghue, M. J ., and Kim, J . (1995). Separate versus combined analysis of phylogenetic evidence. Annu. Rev. Ecol. Syst. 26: 657- 681.

Doyle, J . J . (1992). Gene trees and species trees: Molecular systematics as one-character taxonomy. Syst. Bot. 17: 144-163.

Doyle, J . J . (1997). Trees within trees: Genes and species, molecules and morphology. Syst. Biol. 46: 537-553.

Doyle, J . J ., and Doyle, J . L. (1987). A rapid DNA isolation procedure for small quantities of fresch leaf tissue. Phytochem. Bull. 19: 11-15.

Duvigneaud, J . (1992). Le genre Doronicum L. en Belgique et dans les régions voisines. Nat. Mosana 45: 81-92.

Edmondson, J . R. (1973). Notes on Doronicum L. in SW Asia. Notes R. Bot. Gard. Edinburgh 32: 255-258.

Edmondson, J . R. (1975). Doronicum L. In "Flora of Turkey and the East Aegean Islands" (P. H. Davis, Ed.), Vol. 5, pp. 137-145. Edinburgh Univ. Press, Edinburgh.

Edmondson, J . R. (1978). The genus Doronicum L. in I ran. Notes R. Bot. Gard. Edinburgh 37: 67-73.

Eernisse, D., and Kluge, A. G. (1993). Taxonomic congruence versus total evidence, and amniote phylogeny inferred from fossils, molecules, and morphology. Mol. Biol. Evol. 10: 1170-1195.

Farris, J . S. (1969). A successive approximation approach to character weighting. Syst. Zool. 18: 374-385.

Farris, J. S., Källersjö, M., Kluge, A. G., and Bult, C. (1995). Testing significance of incongruence. Cladistics 10: 315-319.

Francisco-Ortega, J ., Santos-Guerra, A., Hines, A., and J ansen, R. K. (1997). Molecular evidence for a Mediterranean origin of the Macaronesian endemic genus Argyranthemum (Asteraceae). Am. J . Bot. 84: 1595-1613.

Francisco-Ortega, J ., Goertzen, L. R., Santos-Guerra, A., Benabid,
A., and J ansen, R. K. (1999). Molecular systematics of the Asteriscus alliance (Asteraceae: I nuleae). I: Evidence from the internal transcribed spacers of nuclear ribosomal DNA. Syst. Bot. 24: 249266.

Hollis, S., and Brummitt, R. K. (1992). "World Geographical Scheme for Recording Plant Distributions," I nternational Working Group on Taxonomic Databases for Plant Sciences, Hunt Institute for Botanical Documentation, Carnegie Mellon University, Pittsburgh.

Huelsenbeck, J. P., Bull, J. P., and Cunningham, C. W. (1996). Combining data in phylogenetic analysis. Trends Ecol. Evol. 11: 152-158.

Imbert, E., Escarré, J ., and Lepart, J . (1996). Achene dimorphism and among-population variation in Crepis sancta (Asteraceae). Int. J. PI. Sci. 157: 309-315.

J ansen, R. K., Holsinger, K. E., Michaels, H. J ., and Palmer, J . D. (1990). Phylogenetic analysis of chloroplast DNA restriction site data at higher taxonomic levels: An example from the Asteraceae. Evolution 44: 2089-2105.

J ansen, R. K., Michaels, H. J ., and Palmer, J . D. (1991). Phylogeny and character evolution in the Asteraceae based on chloroplast DNA restriction site mapping. Syst. Bot. 16: 98-115.

J effrey, C. (1987). Developing descriptors for systematic analyses of Senecioneae (Compositae). Bot. J ahrb. Syst. 108: 201-211.

J ohnson, L. A., and Soltis, D. E. (1998). Assessing congruence: Empirical examples from molecular data. In "Molecular Systematics of Plants II. DNA Sequencing" (D. E. Soltis, P. S. Soltis, and J . J . Doyle, Eds.), pp. 297-348. Kluwer Academic, Boston.

Kadereit, J. W., and J effrey, C. (1996). A preliminary analysis of cpDNA variation in the tribe Senecioneae (Compositae). In "Compositae: Systematics. Proceedings of the International Compositae Conference, Kew, 1994" (D. J . N. Hind and H. J . Beentje, E ds.), pp. 349-360. Royal Botanic Gardens, Kew.

Kim, K. J ., and J ansen, R. K. (1994). Comparisons of phylogenetic hypothesis among different data sets in dwarf dandelions (Krigia, Asteraceae): Additional information from internal transcribed spacer sequences of nuclear ribosomal DNA. PI. Syst. Evol. 190: 157-185.

Kim, K. J ., and J ansen, R. K. (1995). ndhF sequence evolution and the major clades in the sunflower family. Proc. Natl. Acad. Sci. USA 92: 10379-10383.

Kim, K. J ., J ansen, R. K., Wallace, R. S., Michaels, H. J ., and Palmer, J . D. (1992). Phylogenetic implications of rbcL sequence variation in the Asteraceae. Ann. Missouri Bot. Gard. 79: 428- 445.

Kim, S.-C., Crawford, D., J ., and J ansen R. K. (1996). Phylogenetic relationships among the genera of the subtribe Sonchinae (Asteraceae): Evidence from ITS sequences. Syst. Bot. 21: 417- 432.

Kim, S.-C., Crawford, D. J ., Tadesse, M., Berbee, M., Ganders, F. R., Pirseyedi, M., and Esselman, E. (1999). ITS sequences and phylogenetic relationships in Bidens and Coreopsis (Asteraceae). Syst. Bot. 24: $480-493$.

Kluge, A. G., and Wolf, A. J . (1993). Cladistics: What's in a word? Cladistics 9: 183-199.

Knox, E. B. (1996). What is the origin of the giant senecios in eastern Africa? In "Compositae: Systematics. Proceedings of the International Compositae Conference, Kew, 1994" (D. J . N. Hind and H. J . Beentje, Eds.), pp. 691-703. Royal Botanic Gardens, Kew.

Kornkven, A. B., Watson, L. E., and Estes, J . R. (1998). Phylogenetic analysis of Artemisia section tridentatae (Asteraceae) based on sequences from the internal transcribed spacers (ITS) of the nuclear ribosomal DNA. Am. J . Bot. 85: 1787-1795.

Kubicka, E., Kubicka, G., and McMorris, F. R. (1995). An algorithm to find agreement subtrees. J . Classif. 12: 91-99.

Maddison, D. R. (1991). The discovery and importance of multiple islands of most-parsimonious trees. Syst. Zool. 40: 315-328. 
Maddison, W. P. (1997). Gene trees in species trees. Syst. Biol. 46: 523-536.

Mickevich, M. F., and Farris, J . S. (1981). The implications of congruence in Menidia. Syst. Zool. 30: 351-370.

Miyamoto, M. M., and Fitch, W. M. (1995). Testing species phylogenies and phylogenetic methods with congruence. Syst. Biol. 44: 64-76.

Mort, M. E., Soltis, P. S., Soltis, D. E., and Mabry, M. L. (2000). Comparison of three methods for estimating internal support on phylogenetic trees. Syst. Biol. 49: 160-171.

Nixon, K. C., and Carpenter, J . M. (1996). On simultaneous analysis. Cladistics 12: 221-241.

Nordenstam, B. (1977). Senecioneae and Liabeae systematic review. In "The Biology and Chemistry of the Compositae" (V. H. Heywood, J . B. Harborne, and B. L. Turner, Eds.), pp. 799-830. Academic Press, London.

Olmstead, R. G., and Sweere, J . A. (1994). Combining data in phylogenetic systematics: An empirical approach using three molecular data sets in the Solanaceae. Syst. Bot. 43: 467- 481.

Panero, J. L., Francisco-Ortega, J ., J ansen, R. K., and SantosGuerra, A. (1999). Molecular evidence for multiple origins of woodiness and a new biogeographic connection of the Macaronesian island endemic Pericallis. Proc. Natl. Acad. Sci. USA 96: 1388613891.

Patterson, C. (1988). Homology in classical and molecular biology. Mol. Biol. Evol. 5: 603- 625.

Patterson, C., Williams, D. M., and Humphries, C. J . (1993). Congruence between molecular and morphological phylogenies. Annu. Rev. Ecol. Syst. 24: 153-188.

Pérez Morales, C., and Penas, A. (1990). Sobre algunos Doronicum ibéricos. Lagascalia 15: 151-160.

Pérez Morales, C., and Penas, A., Llamas, F., and Acedo, C. (1994). Doronicum pubescens sp. nov. Lazaroa 14: 5-12.

Pinna, M. C. C. de (1991). Concepts and tests of homology in the cladistic paradigm. Cladistics 7: 367-394.

Robinson, D. F., and Foulds, L. R. (1981). Comparison of phylogenetic trees. Math. Biosci. 53: 131-147.

Sanderson, M. J., and Donoghue, M. J. (1996). The relationship between homoplasy and confidence in a phylogenetic tree. In "Homoplasy: The Recurrence of Similarity in Evolution" (M. J . Sanderson and L. Hufford, Eds), pp. 67- 89. Academic Press, San Diego.

Sanger, F., Nicklen, S., and Coulson, A. R. (1977). DNA sequencing with chain-terminating inhibitors. Proc. Natl. Acad. Sci. USA 74: 5463-5467.

Shinozaki, K., Ohme, M., Tanaka, M., Wakasugi, T., Hayashida, N., Matsubayashi, T., Zaita, N., Chungwonse, J., Obokata, J.,
Yamaguchi-Shinozaki, K., Ohto, C., Torazawa, K., Meng, B.-Y., Sugita, M., Deno, H., Kamogashira, T., Yamada, K., Kusuda, J ., Takaiwa, F., Kato, A., Tohdoh, N., Shimada, H., and Sugiura, M. (1986). The complete nucleotide sequence of the tobacco chloroplast genome: Its gene organization and expression. EMBO J . 5: 2043-2049.

Slowinski, J. B., and Page, R. D. M. (1999). How should species phylogenies be inferred from sequence data? Syst. Biol. 48: 814825.

Soltis, D. E., Soltis, P. E., Mort, M. E., Chase, M. W., Savolainen, V., Hoot, S. B., and Morton, C. M. (1998). I nferring complex phylogenies using parsimony: An empirical approach using three large DNA data sets for angiosperms. Syst. Biol. 47: 32- 42.

Susanna, A., García J acas, N., Soltis, D. E., and Soltis, P. S. (1995). Phylogenetic relationships in tribe Cardueae (Asteraceae) based on ITS sequences. Am. J . Bot. 82: 1056-1068.

Swofford, D. L. (1991). When are phylogeny estimates from molecuIar and morphological data incongruent?. In "Phylogenetic Analysis of DNA Sequences" (M. M. Miyamoto and J . Cracraft, Eds.), pp. 295-333. Oxford Univ. Press, New York.

Swofford, D. L. 2000. PAUP*. Phylogenetic Analysis Using Parsimony (* and Other Methods). Version 4. Sinauer, Sunderland, MA.

Taberlet, P., Gielly, L., Pautou, G., and Bouvet, J . (1991). Universal primers for amplification of three non-coding regions of chloroplast DNA. PI. Mol. Biol. 17: 1105-1109.

Torrell, M., García-J acas, N., Susanna, A., and Vallés, J . (1999). Phylogeny in Artemisia (Asteraceae, Anthemideae) inferred from nuclear ribosomal DNA (ITS) sequences. Taxon 48: 721-736.

Venable, D. L., and Levin, D. A. (1985). Ecology of achene dimorphism in Heterotheca latifolia. J . Ecol. 73: 133-145.

Wendel, J . F., and Doyle, J . J . (1998). Phylogenetic incongruence: Window into genome history and molecular evolution. In "Molecular Systematics of Plants II. DNA Sequencing" (D. E. Soltis, P. S. Soltis, and J.J. Doyle, Eds.), pp. 265-296. Kluwer Academic, Boston.

White, T. J ., Bruns, T., Lee, S., and Taylor, J . (1990). Amplification and direct sequencing of fungal ribosomal RNA genes for phylogenetics. In "PCR Protocols: A Guide to Methods and Applications" (M. A. Innis, D. H. Gelfand, J . J . Sninsky, and T. J . White, Eds.), pp. 315-322, Academic Press, New York.

Widder, F. J . (1925). Eine neue Pflanze der Ostalpen-Doronicum (Subsectio Macrophylla) cataractarum-und ihre Verwandten. Repert. Spec. Nov. Regni Veg. 22: 113-184.

Wiens, J . J . (1998). Combining data sets with different phylogenetic histories. Syst. Biol. 47: 568-581.

Zohary, M. (1950). Evolutionary trends in the fruiting head of Compositae. Evolution 4: 103-109. 